\title{
Astrocytic YAP Promotes the Formation of Glia Scars and Neural Regeneration after Spinal Cord Injury
}

\author{
Changnan Xie, ${ }^{1,2 *}$ Xiya Shen, ${ }^{2,3 *}$ Xingxing Xu, ${ }^{2 \star}$ Huitao Liu, ${ }^{1,2}$ Fayi Li, ${ }^{1,2}$ Sheng Lu, ${ }^{1,2}$ Ziran Gao, ${ }^{4}$ Jingjing Zhang, ${ }^{2}$ \\ Qian Wu, ${ }^{5}$ Danlu Yang, ${ }^{2}$ Xiaomei Bao, ${ }^{2}$ Fan Zhang, ${ }^{2}$ Shiyang Wu, ${ }^{1}$ Zhaoting Lv, ${ }^{5}$ Minyu Zhu, ${ }^{1}$ Dingjun Xu, ${ }^{1}$ \\ Peng Wang, ${ }^{1}$ Liying Cao, ${ }^{3}$ Wei Wang, ${ }^{5}$ Zengqiang Yuan, ${ }^{6}$ Ying Wang, ${ }^{7}$ Zhaoyun Li, ${ }^{8}$ Honglin Teng, ${ }^{1}$ \\ and Zhihui Huang1,2,3 \\ ${ }^{1}$ Department of Spine Surgery, Wenzhou Medical University First Affiliated Hospital, Wenzhou, Zhejiang 325000, China, ${ }^{2}$ School of Basic Medical Sciences, \\ Wenzhou Medical University, Wenzhou, Zhejiang 325035, China, ${ }^{3}$ Key Laboratory of Elemene Anti-cancer Medicine of Zhejiang Province and Holistic \\ Integrative Pharmacy Institutes, Hangzhou Normal University, Hangzhou 311121, China, ${ }^{4}$ Graduate School of Youjiang Medical University for \\ Nationalities, Basie, Guangxi 533000, China, ${ }^{5}$ School of Mental Health, Wenzhou Medical University, Zhejiang 325035, China, ${ }^{6}$ The Brain Science Center, \\ Beijing Institute of Basic Medical Sciences, Beijing 100850, China, ${ }^{7}$ Department of Transfusion Medicine, Zhejiang Provincial People’s Hospital of \\ Hangzhou Medical College, Hangzhou 310053, China, and ${ }^{8}$ Department of Clinical Laboratory, Taizhou Central Hospital (Taizhou University Hospital), \\ Taizhou 318000, Zhejiang, China
}

Yes-associated protein (YAP) transcriptional coactivator is negatively regulated by the Hippo pathway and functions in controlling the size of multiple organs, such as liver during development. However, it is not clear whether YAP signaling participates in the process of the formation of glia scars after spinal cord injury (SCI). In this study, we found that YAP was upregulated and activated in astrocytes of C57BL/6 male mice after SCI in a Hippo pathway-dependent manner. Conditional knockout (KO) of yap in astrocytes significantly inhibited astrocytic proliferation, impaired the formation of glial scars, inhibited the axonal regeneration, and impaired the behavioral recovery of C57BL/6 male mice after SCI. Mechanistically, the bFGF was upregulated after SCI and induced the activation of YAP through RhoA pathways, thereby promoting the formation of glial scars. Additionally, YAP promoted bFGF-induced proliferation by negatively controlling nuclear distribution of $\mathrm{p} 27^{\text {Kip } 1}$ mediated by CRM1. Finally, bFGF or XMU-MP-1 (an inhibitor of Hippo kinase MST1/2 to activate YAP) injection indeed activated YAP signaling and promoted the formation of glial scars and the functional recovery of mice after SCI. These findings suggest that YAP promotes the formation of glial scars and neural regeneration of mice after SCI, and that the bFGF-RhoA-YAP-p27 ${ }^{\text {Kipl }}$ pathway positively regulates astrocytic proliferation after SCI.

Key words: astrocytes; CRM1; $\mathrm{p}^{27^{\text {Kip1 }}}$; proliferation; spinal cord injury; YAP

\section{Significance Statement}

Glial scars play critical roles in neuronal regeneration of CNS injury diseases, such as spinal cord injury (SCI). Here, we provide evidence for the function of Yes-associated protein (YAP) in the formation of glial scars after SCI through regulation of astrocyte proliferation. As a downstream of bFGF (which is upregulated after SCI), YAP promotes the proliferation of astrocytes through negatively controlling nuclear distribution of $\mathrm{p} 27^{\mathrm{Kip} 1}$ mediated by CRM1. Activation of YAP by bFGF or XMU-MP-1 injection promotes the formation of glial scar and the functional recovery of mice after SCI. These results suggest that the bFGF-RhoA-YAPp $27^{\text {Kipl }}$ axis for the formation of glial scars may be a potential therapeutic strategy for SCI patients.

\section{Introduction}

Astrocytes are star-shaped cells surrounding neurons in the brain and the spinal cord. They perform diverse functions in the mam-

Received Sept. 15, 2019; revised Feb. 3, 2020; accepted Feb. 5, 2020.

Author contributions: C.X., X.S., X.X., Z.Y., Y.W., Z.L., H.T., and Z.H. designed research; C.X., X.S., X.X., L.C., W.W., Z.Y., Y.W., Z.L., H.T., and Z.H. performed research; C.X., X.S., X.X., H.L., F.L., S.L., J.Z., Q.W., D.Y., X.B., F.Z., S.W., Z.L., M.Z., D.X., P.W., L.C., W.W., and Z.H. contributed unpublished reagents/analytic tools; C.X., X.S., H.L., F.L., S.L., Z.G., malian CNS under physiological and pathological conditions (Sofroniew and Vinters, 2010; Pekny et al., 2016). In a healthy CNS, astrocytes regulate metabolism, support the structure, modulate synaptic transmission, and maintain the blood-brain

J.Z., Q.W., D.Y., X.B., F.Z., S.W., Z.L., M.Z., D.X., P.W., L.C., and W.W. analyzed data; C.X. wrote the first draft of the paper; C.X. edited the paper; C.X. wrote the paper.

This work was supported by the Natural Science Foundation of Zhejiang Province (LR18C090001, LY18C090004), the National Natural Science Foundation (31671071, 81571190, 81771348, 81701202), the Research Start-up Project by Wenzhou Medical University (89217022) and the Research Start-up Project by Hangzhou normal University 
barrier (Sofroniew and Vinters, 2010; Khakh and Sofroniew, 2015; Chen et al., 2018a). Under CNS pathology, astrocytes have diverse functions, including changes in neurotrophic factor secretion, elimination of waste debris and dead cells, repair of the blood-brain barrier, and formation of glial scars (Sofroniew and Vinters, 2010). Following traumatic injuries of the CNS, including spinal cord injury (SCI) (Okada et al., 2018; Li et al., 2019), different gradations of glial scars are varied with insult severity (Sofroniew, 2014), and severe injury promotes the proliferation of astrocytes forming a dense glial barrier, which protects healthy tissue against inflammation over long periods (Yiu and $\mathrm{He}$, 2006). However, in the past, barriers created by scar-forming astrocytes have been proposed as the primary causes of axon regeneration failure after SCI (Yiu and He, 2006; Fitch and Silver, 2008). Astrocytes within the scars secrete several growthinhibitory molecules, such as chondroitin sulfate proteoglycans (GSPGs) and semaphorin 3A, which prevent the neural recovery of the CNS after injury or disease (Stichel and Müller, 1998; Silver and Miller, 2004; Kaneko et al., 2006; Gaudet and Fonken, 2018; Tran et al., 2018). There are common features of severe diffuse glial scars: appearance of lesion site of the scar border, upregulation of GFAP and vimentin, cellular hypertrophy, and newly proliferated astrocytes (Sofroniew, 2014; Chen et al., 2018b). Additionally, there is compelling evidence showing that glial scars are associated with signal transducers and activators of transcription-3 (STAT-3), C5aR, nuclear factor $\kappa \mathrm{B}$, and leucine zipper-bearing kinase (LZK) after SCI (Herrmann et al., 2008; Sofroniew, 2009; Brennan et al., 2015; Chen et al., 2018b) with either beneficial or detrimental effects on neural regeneration. Therefore, understanding the roles of glial scars and the underlying molecular mechanisms will guide in the design of therapeutic intervention strategies to accelerate recovery after traumatic injuries and diseases of CNS.

The Hippo/Yes-associated protein (YAP) signaling pathway controls organ sizes in mammals by regulating cell differentiation, proliferation, and apoptosis (Cai et al., 2010; Pan, 2010; Johnson and Halder, 2014; Yu et al., 2015). Activation of the Hippo/YAP kinase cascade induces phosphorylation of YAP and subsequent proteasomal degradation or cytoplasmic retention. On the contrary, blocking of the Hippo pathway, for instance, through the suppression of MST1/MST2 and LATS1/LATS2, promotes entry of YAP into the nuclei, which interacts with TEAD family proteins to initiate gene expression (Piccolo et al., 2014; Maugeri-Saccà and De Maria, 2018). Most studies on YAP previously focused on tumorigenesis, since the upregulation of YAP promotes cell growth and inhibits apoptosis of tumor cells (Lau et al., 2014; Zanconato et al., 2016). For CNS injuries, MST1 and LATS1 have detrimental effects on neural recovery after traumatic brain injury and SCI (M. Zhang et al., 2017; Li et al., 2018; Qu et al., 2018; Y. Wang and Chen, 2018). Our recent studies indicate that YAP participates in astrocytic differentiation of the developing mouse cortex via BMP2-YAP-SMAD1 pathway (Huang et al., 2016b). However, the functions and mechanisms

(4125C5021920453), the Science and Technology Planning Project of Zhejiang Province (2017C33197), and the Foundation of Zhejiang Educational Committee (Y201636785). We thank Prof. Chuanshu Huang (New York University School of Medicine) for gifting the EGFP-p27 ${ }^{\text {Kip } 1}$ plasmid.

The authors declare no competing financial interests.

${ }^{*}$ C.X., X.S., and X.X. contributed equally to this work.

Correspondence should be addressed to Honglin Teng at honlinten@163.com or Zhihui Huang at hzhzju021@163.com.

https://doi.org/10.1523/JNEUROSCI.2229-19.2020

Copyright $\odot 2020$ the authors of YAP, for instance, in regulation of the formation of glial scars after SCI, remain poorly understood.

In this study, we found that YAP was upregulated and selectively activated in astrocytes in a Hippo kinase-dependent manner after SCI. Conditional KO of yap in astrocytes inhibited the formation of glial scars through the reduction of astrocytic proliferation, resulting in the inhibition of axonal regeneration and impairment of the behavioral recovery following SCI. Mechanistically, bFGF was upregulated after SCI and promoted the formation of glial scars via YAP signaling. Further, YAP promoted bFGF-induced astrocytic proliferation through negatively controlling nuclear distribution of p $27^{\text {Kip } 1}$ mediated by CRM1.

\section{Materials and Methods}

Animals and mice breeding. The $y a p^{G F A P}$-CKO conditional KO mice were produced by crossing floxed yap allele $\left(y a f^{f / f}\right)$ with GFAP-Cre transgenic mice (Shanghai Model Organisms). The yap ${ }^{f / f}$ mice were generated as previously described (Y. Wang et al., 2014; Huang et al., 2016a,b). Both the $y a p^{f / f}$ and $y a p^{G F A P}-C K O$ mice were maintained in C57BL/6 strain background. All comparisons were made between C57BL/6 WT male mice, $y a p^{f / f}$, and $y a p^{G F A P}$-CKO male mice. We obtained approval of this study from the Laboratory Animals Ethics Committee of Wenzhou Medical University (WYDW-2015-0150).

SCI surgical procedures and treatment. The clip-compressive SCI model was described in previous studies (Mao et al., 2010; Marques et al., 2010; de Almeida et al., 2011; Y. F. Wang et al., 2014). Briefly, all animals $\left(\mathrm{WT}, y a p^{f / f}\right.$, and $y a p^{G F A P}-\mathrm{CKO}$ male mice) were subjected to general anesthesia $(20 \mathrm{ml} / \mathrm{kg})$ by intraperitoneal injection of avertin $(2,2$, 2 -tribromoethanol, Sigma Millipore) in $0.9 \%$ saline solution. A laminectomy from $\mathrm{T} 8$ to $\mathrm{T} 9$ was performed using a surgical microscope (Nikon, SMZ745) and mouse spinal cord adapter (RWD, 68094). The spinal cord was compressed by a vascular clip (30 G force, Kent Scientific) for $15 \mathrm{~s}$ (Joshi and Fehlings, 2002a,b; Marques et al., 2009) (see Fig. 1 A,B). After SCI, the bladder was manually evacuated twice on a daily basis until the restoration of the urinating function. All animals in the sham group were subjected to laminectomy alone. For bFGF injection after SCI, recombinant human bFGF, purchased from Sigma Millipore, was injected subcutaneously near the back wound at a dose of $80 \mu \mathrm{g} / \mathrm{kg}$ at $30 \mathrm{~min}$ after injury (Ye et al., 2016), as described in previous studies that the subcutaneous injection of bFGF can cross the blood-brain barrier (Tao et al., 1996; Wagner et al., 1999; Ye et al., 2010) and effectively improved the functional recovery and increased the survival of neurons in a rat model of SCI (H. Y. Zhang et al., 2013a,b; Ye et al., 2016). Subsequently, the bFGF was injected every $2 \mathrm{~d}$ until the animals were killed. For XMUMP-1 (Medchemexpress, Y-100526) treatment after SCI, XMU-MP-1 was dissolved in DMSO and injected intraperitoneally at a dose of 1 $\mathrm{mg} / \mathrm{kg}$ (Fan et al., 2016), given every $2 \mathrm{~d}$, as described in previous studies that the intraperitoneal injection of XMU-MP-1 alleviated the neurological deficits, blood-brain barrier disruption, brain edema, neuroinflammation, and white matter injury after subarachnoid hemorrhage in mice (Qu et al., 2018), which suggest that XMU-MP-1 may be able to cross the blood-brain barrier and effectively reduce brain injury. All animals were randomly distributed into experimental groups. Blind evaluation to genotype and experimental condition was performed. The mice were used to assess histological, biochemical, and behavioral functions.

Behavioral analysis. The motor function and sensory function of mice were evaluated using five behavioral tests described below on days $0,3,7$, 14 , and 28 after SCI.

Open-field locomotor task. The objective was to assess gross voluntary use of the hindlimbs, and did not attempt to define subtle differences in usage that might be correlated with specific neural mechanisms that might underlie dysfunctions. We used a simple 6 point scale, as previously described (Fehlings and Tator, 1995). Briefly, all animals were evaluated in an open field by the same one or two observers blind to the experimental conditions and received a score for gross voluntary movement of each hindlimb using an operationally defined 6 point scale: $(0)$ no voluntary hindlimb movement, (1) little voluntary hindlimb movement, (3) hindlimb assisted in occasional weight support and plantar 
placement but not in stepping, (4) hindlimb used for weight support and stepping, but obvious disability, and (5) hindlimb function essentially normal (Fehlings and Tator, 1995).

Footprint analysis. To assess the athletic ability of forelimbs and hindlimbs after SCI, the mice were put to run along a paper-lined runway, as described previously (Ma et al., 2001; Faulkner et al., 2004). Briefly, after each forelimb and hindlimb were brushed with black (forelimbs) and red (hindlimbs) nontoxic ink, the animals were required to run along a paper-lined runway ( 3 feet long, 3 inches wide) in a darkened box at the end. The plantar stepping, stride length and width, and overall stepping ability were qualitatively analyzed.

Rotarod performance. To evaluate balance, grip strength, and motor coordination, the animals were placed on a single-lane rotarod (Anhui Zhenghua Biological Instrument Equipment, YLS-10A) for three trials per session, which was set for 3.0-30 rpm over $180 \mathrm{~s}$. Time taken to fall was scored. Each trial was scored individually and averaged for a final score per session.

Pole test. To evaluate balance and coordination in genetic $\mathrm{KO}$ animals compared with WT mice, the animals were placed on a $50-\mathrm{cm}$-high pole, and the time all the four limbs took to land on was recorded. Whenever the animal paused and descended with a lateral body position instead of turning, the trial was repeated. The time for each trial was scored individually and averaged for a final score per session.

Mechanical sensitivity. The tactile sensitivity of the hindlimb was assessed in a subset of the animals $\left(y a p^{f / f}\right.$ male mice, $y a p^{G F A P}$-CKO male mice, bFGF-treated and XMU-MP-1-treated WT male mice) using von Frey hair (Faw et al., 2018; Xu et al., 2019). Briefly, the mice were placed under a small, opaque container on an elevated wire mesh to allow access to the plantar surface of the paws. The animals acclimated to the experimental conditions for $30 \mathrm{~min}$ before testing. The hindpaws were assessed using the up/down method, beginning with the application of $0.4 \mathrm{~g}$ filament to the plantar L5 dermatome. Each hindpaw received 10 consecutive treatments. Additional trials were performed as needed to achieve a $50 \%$ withdrawal threshold, which was determined as the lowest force evoking withdrawal in at least half of the trials for that force. The dorsal von Frey method was used in assessing the mechanical sensitivity of mice.

Primary astrocyte culture and transfection. Primary astrocyte cultures were prepared from the spinal cord of P1-P3 mice as described previously (Huang et al., 2016b). Briefly, the spinal cords were dissociated, chopped, and then incubated in $0.125 \%$ trypsin (Invitrogen) at $37^{\circ} \mathrm{C}$ for $20 \mathrm{~min}$, and dissociated into a single-cell suspension by mechanical disruption. The cells were seeded on poly-L-lysine $(0.1 \mathrm{mg} / \mathrm{ml}$, Sigma Millipore)coated culture flasks and cultured with DMEM containing 10\% FBS (Invitrogen). After 6-10 d, other glial cells were removed by shaking at $250 \mathrm{rpm}$ for $4-6 \mathrm{~h}$. The astrocytes were detached and plated into polyL-lysine-coated dishes or coverslips. The purity of GFAP ${ }^{+}$cells in our culture system was $>94 \%$.

For bFGF treatment $(100 \mathrm{ng} / \mathrm{ml}$, Invitrogen), astrocytes were starved with DMEM without serum media for $24 \mathrm{~h}$ before bFGF treatment at various time points $(0,0.5$, and $1 \mathrm{~h})$. For Y27632 treatment (10 $\mu \mathrm{M}$, Sigma Millipore), astrocytes after bFGF treatment or not were preincubated in Y27632 for at least $30 \mathrm{~min}$. For cycloheximide (CHX) (100 $\mu \mathrm{M}$, Medchemexpress, HY-12320) treatment, astrocytes after bFGF treatment or not were incubated with $\mathrm{CHX}$ at the indicated time points. For leptomycinB (LMB) ( $5 \mathrm{ng} / \mathrm{ml}$, Beyotime), astrocytes after bFGF treatment or not were preincubated in LMB for $6 \mathrm{~h}$. For transfection, astrocytes were grown in DMEM (Invitrogen) and supplemented with 10\% FBS (Invitrogen) and $1 \%$ penicillin/streptomycin (Invitrogen) in a $5 \% \mathrm{CO}_{2}$ incubator at $37^{\circ} \mathrm{C}$. Appropriate plasmids $(4 \mu \mathrm{g}$ per $60 \mathrm{~mm}$ dish) were transfected into the cells using Lipofectamine 3000 Transfection Reagent (L3000-015, Invitrogen) according to the manufacturer's instructions.

Western blot. The spinal cords or cultured astrocytes were lysed in the lysis buffer: ice-cold RIPA buffer (P0013B, Beyotime), $100 \mathrm{~mm} \mathrm{NaF}, 100$ $\mathrm{mM} \mathrm{Na}_{3} \mathrm{VO}_{4}, 100 \mathrm{~mm}$ PMSF, and incubated at $4^{\circ} \mathrm{C}$ for $30 \mathrm{~min}$, and extracted with $5 \times$ loading buffer. Finally, the proteins were boiled at $100^{\circ} \mathrm{C}$ for $10 \mathrm{~min}$. The samples were separated using $8 \%, 10 \%$, or $12 \%$ SDS-PAGE and transferred onto nitrocellulose membranes (Life Sciences). After blocking in 5\% skim milk for $1.5 \mathrm{~h}$, immunoblots were incubated overnight at $4^{\circ} \mathrm{C}$, with different primary antibodies. Subse- quently, the plates were washed thrice and incubated with the HRPconjugated secondary antibodies (1:10,000, Pierce) for $1.5 \mathrm{~h}$. The primary antibodies included rabbit anti-YAP (ab205270, Abcam, 1:1000), rabbit anti-p-YAP (\#13008, Cell Signaling Technology, 1:1000), rabbit anti-LATS1 (\#3477, Cell Signaling Technology, 1:1000), rabbit anti-p-LATS1 (ser909) (\#9157, Cell Signaling Technology, 1:1000), rabbit anti-MST1 (\#3682, Cell Signaling Technology, 1:1000), rabbit antip-MST1/2 (Thr183/Thr180) (\#49332, Cell Signaling Technology, 1:1000), rabbit anti-SAV1 (\#13301, Cell Signaling Technology, 1:1000), rabbit anti-MOB1 (\#13730, Cell Signaling Technology, 1:1000), mouse anti-GFAP (MAB360, Millipore, 1:3000), mouse anti-p27 ${ }^{\text {Kip1 }}$ (\#3698, Cell Signaling Technology, 1:1000), mouse anti-CRM1 (sc-74454, Santa Cruz Biotechnology, 1:500), rabbit anti-Lamin B1 (ab16048, Abcam, 1:1000), rabbit anti-vimentin (ab92547, Abcam, 1:1000), mouse anti-Akt (\#2920, Cell Signaling Technology, 1:1000), and rabbit anti-p-AktThr308 (\#13038, Cell Signaling Technology, 1: 1000). Rabbit antiGAPDH (\#2118, Cell Signaling Technology, WB, 1:5000) and mouse anti- $\beta$-actin (A5316, Sigma Millipore, WB 1:10,000) served as loadings control. The Western blot was detected by the ECL detection kit (BioRad). Subsequently, the images were analyzed using the Quantity One software (Bio-Rad).

Nissl staining. Nissl staining was performed as previously described (P. Wang et al., 2018). Briefly, after perfusing the mice with $0.1 \mathrm{~mol} / \mathrm{L}$ PBS followed by $4 \%$ PFA, the spinal cords were immersed in $4 \%$ PFA for $24 \mathrm{~h}$ and transferred to $30 \%$ sucrose where they were immersed. Subsequently, T8-T9 thoracic spinal cords segment were cut into $20-\mu \mathrm{m}$-thick transverse and horizontal sections using a freezing microtome (Thermo Fisher Scientific). The sections were incubated with $0.1 \%$ cresyl violet for $3 \mathrm{~min}$ at room temperature and then rinsed in double-distilled water followed by $95 \%$ ethanol. They were subsequently dehydrated in $100 \%$ ethanol, cleared in xylene, and then covered by neutral resins. For SCI samples, the ventral horn and intermediate gray matter layers of spinal cords were observed. Images were acquired by using a microscope (Nikon), and the number of neurons in ventral horn of spinal cord was counted using the ImageJ software (Media Cybernetics). Quantitative analysis of histological staining and fluorescence was accomplished using ImageJ.

Immunostaining. After perfusing the mice with $0.1 \mathrm{~mol} / \mathrm{L}$ PBS followed by $4 \%$ PFA, the spinal cords were immersed in $4 \%$ PFA for $24 \mathrm{~h}$ and transferred to $30 \%$ sucrose solution until they were immersed. Subsequently, T8-T9 thoracic spinal cords segment were cut into $20 \mu \mathrm{m}$-thick transverse and horizontal sections using a freezing microtome (Thermo Fisher Scientific). For spinal cord tissue section staining, the sections were fixed for $30 \mathrm{~min}$, and the antigens repaired for $30 \mathrm{~min}$ at $90^{\circ} \mathrm{C}$ using Sodium Citrate Antigen Retrieval Solution (Solarbio). Subsequently, the spinal cord tissue sections were processed for $1 \mathrm{~h}$ by blocking in 5\% BSA plus $0.3 \%$ Triton $\mathrm{X}-100$ at room temperature. This was followed by overnight incubation with primary antibodies at $4^{\circ} \mathrm{C}$. They were subsequently washed thrice with PBS, and followed by $1 \mathrm{~h}$ incubation at room temperature with the appropriate secondary antibodies (1:1000, Invitrogen). The primary antibodies included mouse anti-YAP (WH0010413M1, Sigma Millipore, 1:200), mouse anti-GFAP (MAB360, Millipore, 1:500), goat anti-Ibal (ab5076, Abcam, 1:500), rabbit anti-NeuN (ab177487, Abcam, 1:400), rabbit anti-NF200 (ab8135, Abcam, 1:500), rabbit antiGAP43 (ab16053, Abcam, 1:500), rabbit anti-PH3 (06-570, Millipore, 1:200), rabbit anti-Ki67 (RM-9106, Thermo Fisher Scientific, 1:200), and rabbit anti-vimentin (ab92547, Abcam, 1:600). Sections were stained with DAPI (1:1000, Sigma Millipore) to visualize the nucleus. For SCI samples, the ventral horn and intermediate gray matter layers of spinal cords were observed. The images were acquired using DeltaVision Ultra (GE Healthcare) and confocal microscopes (Zeiss) and analyzed with Image and Photoshop (Adobe) software.

For cultured cell staining, the protocols were as described previously (Huang et al., 2016b). Briefly, the cells were rinsed once with PBS and fixed in 4\% PFA for $20 \mathrm{~min}$. Subsequently, they were blocked and permeabilized with $0.1 \%$ Triton X-100 in PBS containing 5\% BSA for $1 \mathrm{~h}$ at room temperature, and incubated overnight with primary antibodies at $4^{\circ} \mathrm{C}$. The cells were subsequently, washed thrice with PBS, and incubated with an appropriate fluorescence-conjugated second antibody (1:1000, 
A

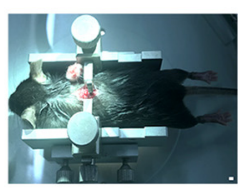

B

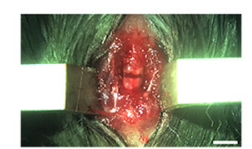

C

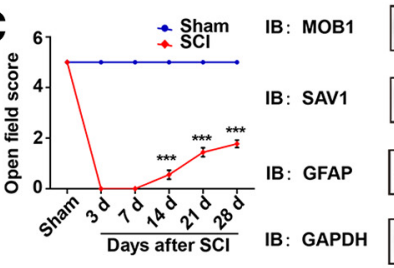

$\mathbf{N}$

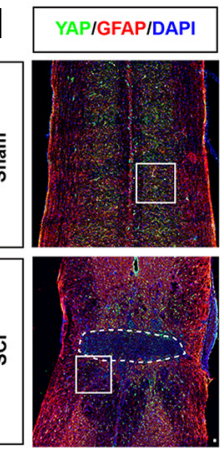

D IB: p-YAP IB: YAP IB: p-LATS1 IB: LATS1 IB: p-MST1/2 IB : MST1

YAP

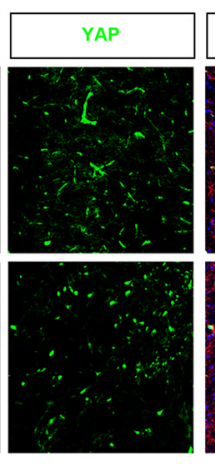

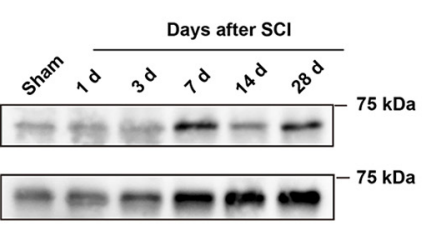

QDenement

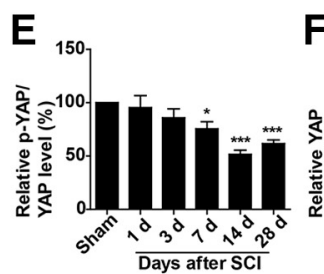

$\mathbf{H}$
$\mathbf{F}$

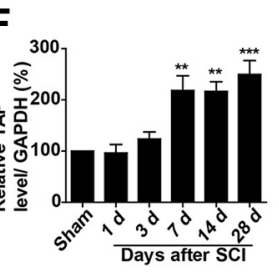

I
G

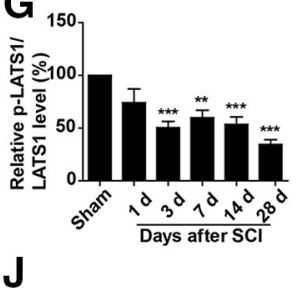

$\mathbf{J}$
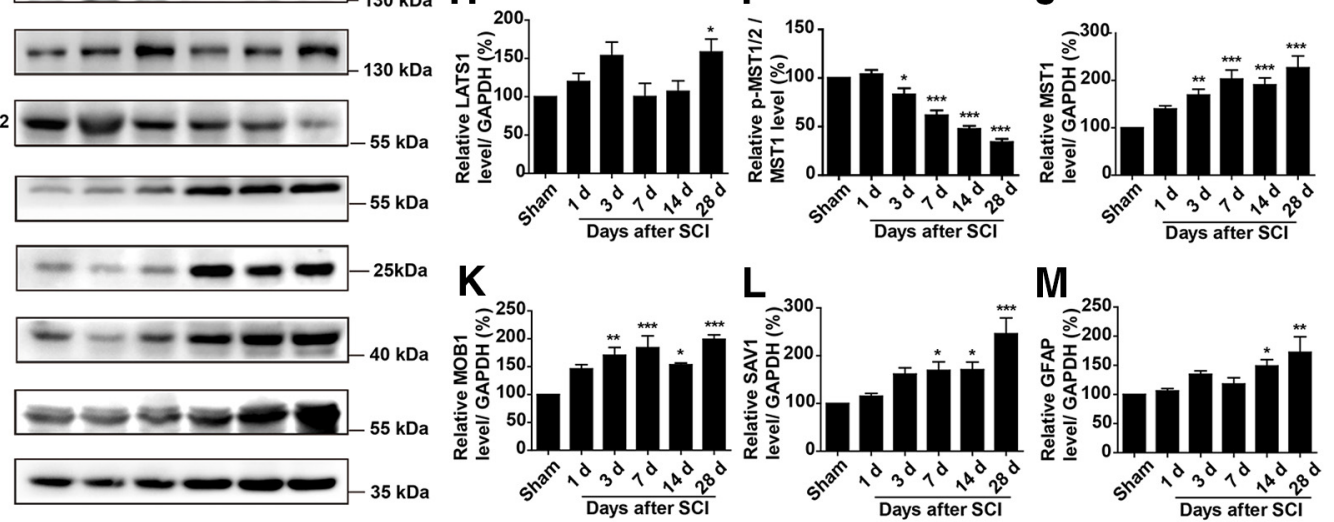

$L_{300} \quad M$
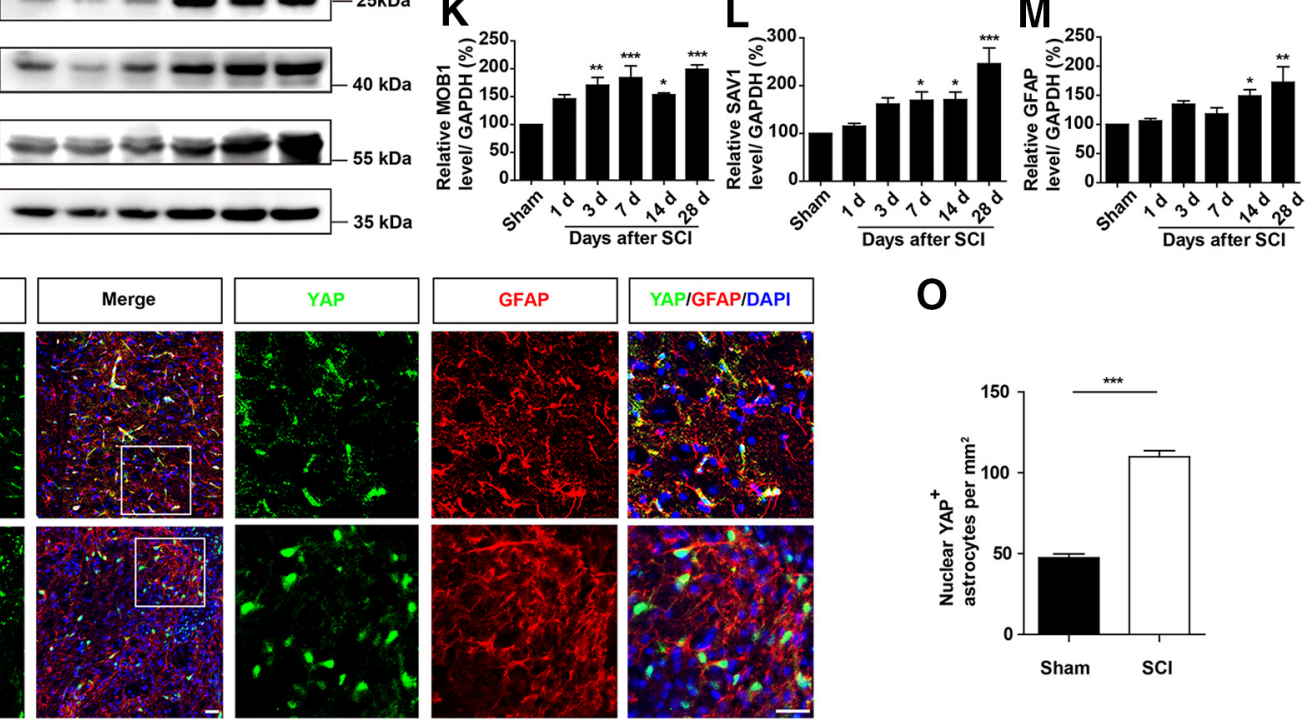

0

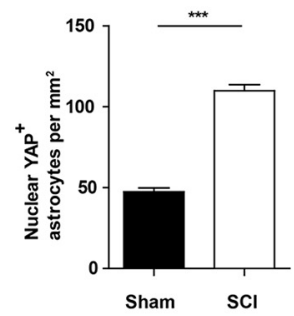

Figure 1. YAP was upregulated and activated in astrocytes after SCl in a Hippo kinase-dependent manner. $\boldsymbol{A}-\boldsymbol{B}$, Typical images showing the clip-compressive SCI model. $\boldsymbol{C}, \mathbf{Q u a n t i t a t i v e ~ a n a l y s i s ~}$ of motor function measured by open field behavioral assays at different stages after $S \mathrm{Cl}$ ( $n=3$ per group). D. Western blot analysis of p-YAP, YAP, p-LATS1, LATS1, p-MST1/2, MST1, SAV1, MOB1, and GFAP expression in spinal cords at different stages after SCl. $\boldsymbol{E}-\boldsymbol{M}$, Quantitative analysis of p-YAP/YAP (E), YAP (F), p-LAST1/LATS1 (G), LATS1 (H), p-MST1/2/MST1 (I), MST1 (J), MOB1 (K), SAV1 $(\boldsymbol{L})$, and GFAP $(\boldsymbol{M})$ protein levels as shown in $\boldsymbol{D}(n=4$ per group). $\boldsymbol{N}$, Double immunostaining of YAP (green) and GFAP (red) in spinal cords $14 \mathrm{~d}$ after SCI. White dashed lines indicate the injury sites. $\boldsymbol{N}$, Images of selected regions (white squares) are shown at higher magnification. $\mathbf{O}$, Quantitative analysis of the number of nuclear YAP-positive astrocytes per $\mathrm{mm}^{2}$ as shown in $\boldsymbol{N}(n=4$ per group). C, Quantitative data were analyzed using two-way ANOVA with Bonferroni post tests. $E-M$, Quantitative data were analyzed using one-way ANOVA with Dunnett's multiple-comparison test. $\mathbf{0}$, Quantitative data were analyzed using Student's unpaired two-tailed $t$ test. ${ }^{*} p<0.05,{ }^{* *} p<0.01,{ }^{* * *} p<0.001$, compared with control. Data are mean \pm SEM. Scale bars: $\boldsymbol{A}, \boldsymbol{B}, 200 \mathrm{~mm} ; \boldsymbol{N}$, $20 \mu \mathrm{m}$.

Invitrogen) at room temperature. The primary antibodies included mouse anti-YAP (WH0010413M1, Sigma Millipore, 1:200), mouse antiGFAP (MAB360, Millipore, 1:500), rabbit anti-PH3 (ab14955, Abcam, 1:200), rabbit anti-Ki67 (RM-9106, Thermo Fisher Scientific, 1:200), and mouse anti-p27 ${ }^{\text {Kip1 }}$ (\#610242, BD Biosciences, 1:200). The sections were stained with DAPI (1:1000, Sigma Millipore) to visualize the nucleus. The images were acquired using fluorescent microscopy and analyzed with ImageJ and Photoshop (Adobe) software.

$q R T-P C R$. Total RNA was extracted from the spinal cord of SCI $(1,3$, 7,14 , and $28 \mathrm{~d}$ ) or astrocytes using TRIzol reagent (\#15596026, Ambion) following the manufacturer's instructions. The RNA was reverse transcribed into cDNA using the SuperScript One-Step Reverse Transcription Kit (\#10928-034, Invitrogen). The expression levels of bFGF and CRM1 mRNA were quantified using the iTaq Universal SYBR Green Supermix (Bio$\mathrm{Rad}$ ) on the Real-Time PCR detection System (Applied Biosystems). The samples were amplified independently at least three times. Relative gene expression was converted using the $2^{-\Delta \Delta \mathrm{Ct}}$ method. The primer used included the following (Corum et al., 2014; Fang et al., 2014; S. Zhang et al., 2017): bFGF primer: forward, 5'-CACCAGGCCACTTCAAGGA-3' and reverse, $5^{\prime}$-GATGGATGCGCAGGAAGAA-3'; CRM1 primer: forward, 5'-AGGAAGGAGCAGTTGGTTCA-3' and reverse, 5'-TATTC
CTTCGCACTGGTTCC-3'; GAPDH primer: forward, 5'-AGGTCGGT GTGAACGGATTTG-3' and reverse, 5'-TGTAGACCATGTAGTTGA GGTCA-3'.

Cytosol-nuclei fractionation. We used the nuclear-cytosol extraction kit (\#P1200, Applygen) to dissociate the cytoplasmic and nuclear proteins following manufacturer's instructions. The fractions were analyzed by SDS-PAGE and Western blot with specific antibodies.

RNA sequencing and functional enrichment analysis. Total RNA was isolated from $y a p^{+/+}$and $y a p^{-/-}$astrocytes using Trizol (Invitrogen) according to the manufacturer's instructions. RNA purity was assessed using the ND-1000 Nanodrop. Each RNA sample had an A260:A280 ratio $>1.8$ and $\mathrm{A} 260$ :A230 ratio $>2.0$. RNA integrity was evaluated using the 2200 TapeStation (Agilent Technologies), and each sample had the RIN >7.0. Briefly, rRNAs were removed from the total RNA using EpicenterRibo-Zero rRNA Removal Kit (Illumina) and fragmented to $\sim 200 \mathrm{bp}$. Subsequently, the purified RNAs were subjected to first-strand and second-strand cDNA synthesis followed by adaptor ligation and enrichment with a low-cycle PCR using the Illumina NEBNext Ultra RNA Library Prep Kit (NEB) following the manufacturer's instructions. The purified double-strand cDNA library products were evaluated using the 2200 TapeStation (Agilent Technologies) and Qubit 2.0 (Invitrogen) 

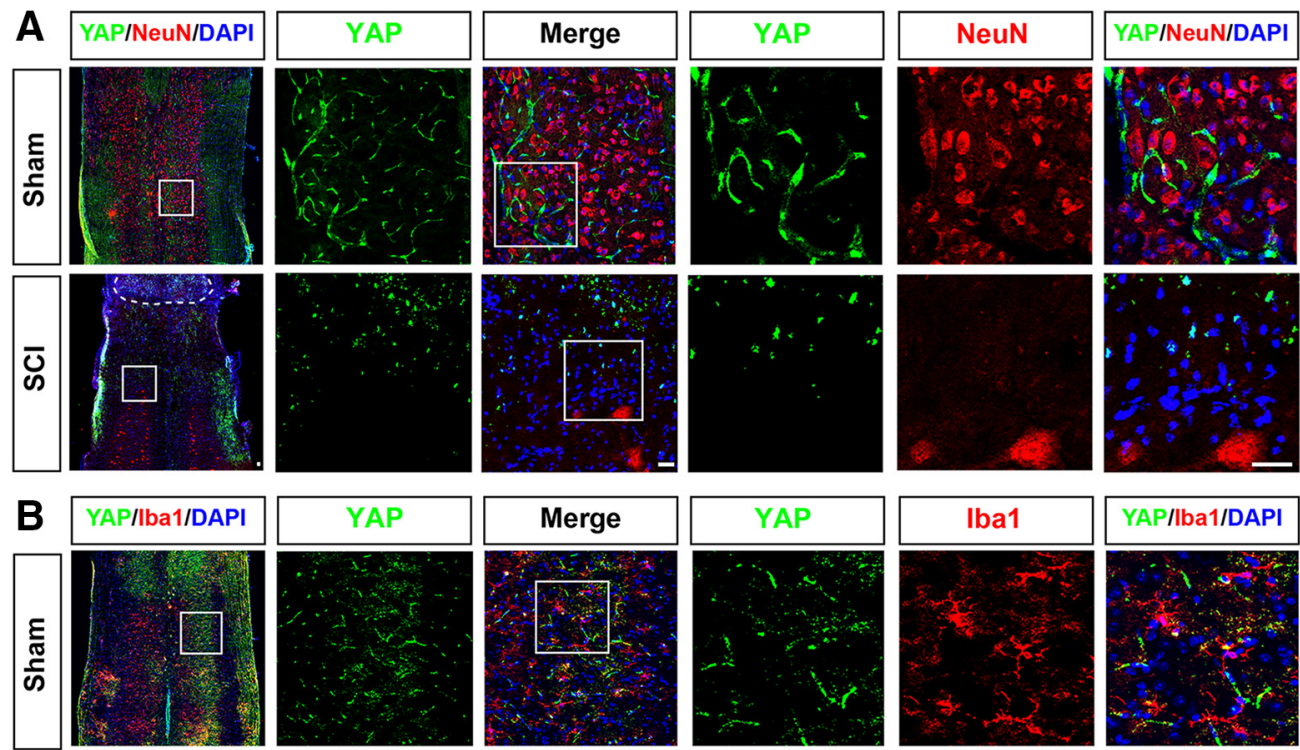

YAP/Iba1/DAPI
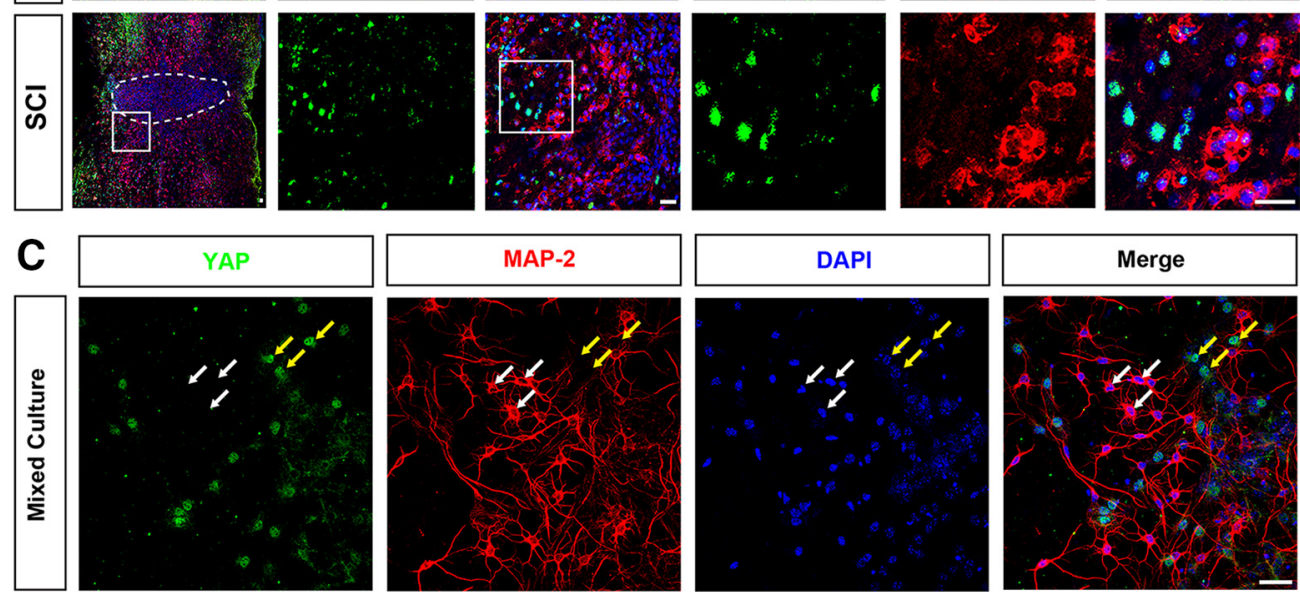

Figure 2. The expression pattern of YAP in spinal cord tissues at $14 \mathrm{~d}$ after $\mathrm{SCl}$ and in primary cultured spinal cord neurons. $\boldsymbol{A}, \boldsymbol{B}$, Double immunostaining of YAP (green) and NeuN (red) (A) or YAP (green) and lba1 (red) (B) in spinal cords at $14 \mathrm{~d}$ after SCI. White dashed lines indicate the injury sites. $\boldsymbol{A}, \boldsymbol{B}$, Images of selected regions (white squares) are shown at higher magnification. $\boldsymbol{C}$, Double immunostaining of YAP (green) and MAP-2 (red) in primary cultured spinal cord neurons. White arrows indicate YAP-negative and MAP-2-positive cells. Yellow arrows indicate YAP-positive and MAP-2-negative cells. Scale bars, $20 \mu \mathrm{m}$.

and then diluted to $10 \mathrm{pm}$ for cluster generation in situ on the pair-end flow cell. End pair sequencing $(2 \times 150 \mathrm{bp})$ was accomplished on HiSeq3000.

The raw data reads were cleaned by removal of adapters, poly- $\mathrm{N}$, and low-quality reads. The cleaned high-quality paired end reads were aligned to the mouse reference genome using HISAT2 (default parameters). HTSeq-count was subsequently used to convert aligned short reads into read counts for each gene model. Differential gene expression analysis was accomplished by DEseq using read counts as input. The Benjamini-Hochberg multiple test correction method was enabled. Differentially expressed genes were chosen according to the criteria of fold change $>2$ and adjusted $p$ value $<0.05$. All the differentially expressed genes were used in the heat map analysis and KEGG ontology enrichment analyses. A $p$ value $<0.05$ was used as the threshold in KEGG enrichment analysis to determine the significant enrichment of the gene sets.

Statistical analysis. All data presented represented results from at least three independent experiments. Student's unpaired two-tailed $t$ test or ANOVA with pairwise comparisons was used in statistical analysis. Statistical significance was defined as $p<0.05$.

\section{Results}

YAP was upregulated and activated in astrocytes after SCI

To explore the functions of YAP after SCI, we first examined the temporal and spatial expression pattern of YAP based on the clip-compressive SCI model. Compared with the contusion SCI model, the clip-compressive SCI model is more suitable in the assessment of the formation of glial scars (Mao et al., 2010; Marques et al., 2010; de Almeida et al., 2011; Y. F. Wang et al., 2014). The moderate-severe crush injury was made by compression from both lateral sides using a vascular clip that caused a clear blockage lesion zone and motor impairments (Fig. 1A-C). Based on this SCI model, the protein samples of spinal cords were collected and the expression of YAP protein and Hippo pathway proteins were assayed by Western blotting at different stages after SCI. We found that the expression of YAP protein was significantly upregulated at the lesion site from $7 \mathrm{~d}$ and with a peak at $28 \mathrm{~d}$ after SCI (Fig. $1 D, F$ ), whereas the relative ratio of phosphoYAP (p-YAP)/YAP was significantly decreased at 7, 14, and $28 \mathrm{~d}$ following SCI (Fig. $1 D, E$ ). The expression pattern of GFAP (glial scar maker) was also significantly upregulated from $14 \mathrm{~d}$, delayed a week than YAP protein (Fig. $1 D, M$ ). Additionally, the Hippo pathway kinase proteins, including LATS1 (Fig. $1 D, H$ ), MST1 (Fig. $1 D, J$ ), MOB1 (Fig. $1 D, K$ ), and SAV1 (Fig. $1 D, L$ ), were significantly upregulated. However, the relative ratio of phosphoLATS1 (p-LATS1)/LATS1 (Fig. 1 D, G) and phospho-MST1/2 (pMST1/2)/MST1 (Fig. 1D,I) gradually declined after SCI. These 
A

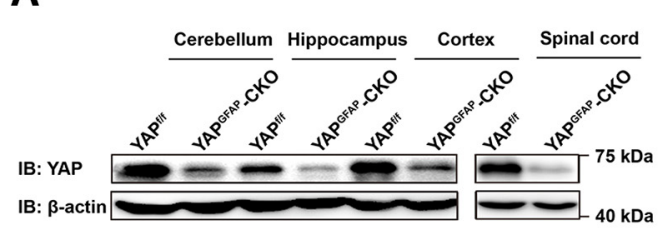

B

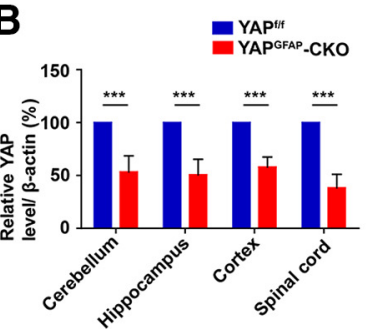

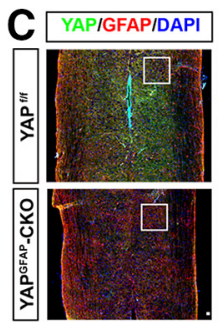

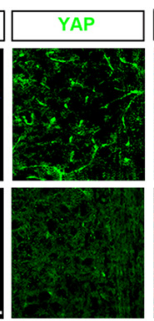

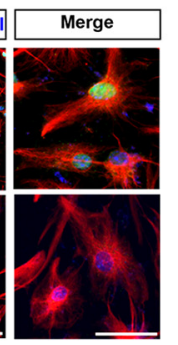

$\mathbf{F}$

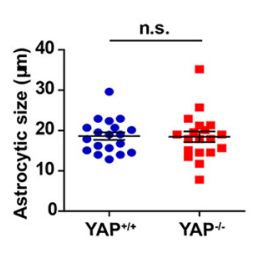

G

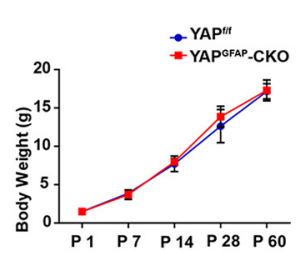

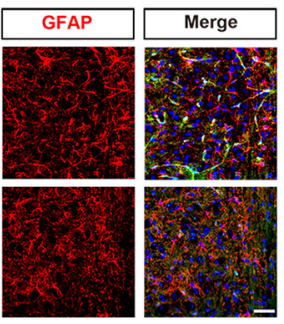

$\mathbf{H}$

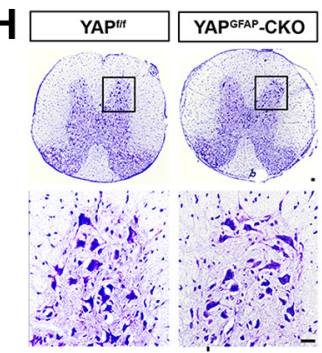

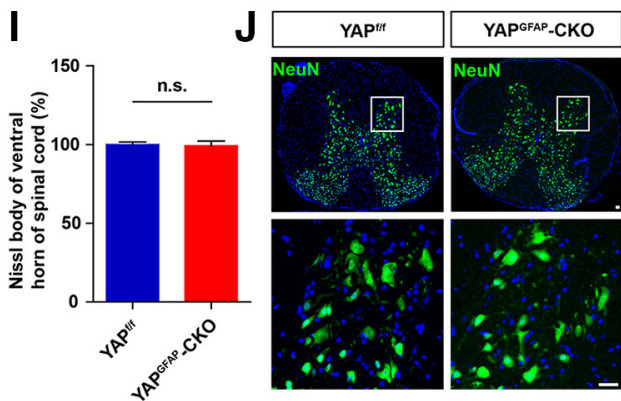
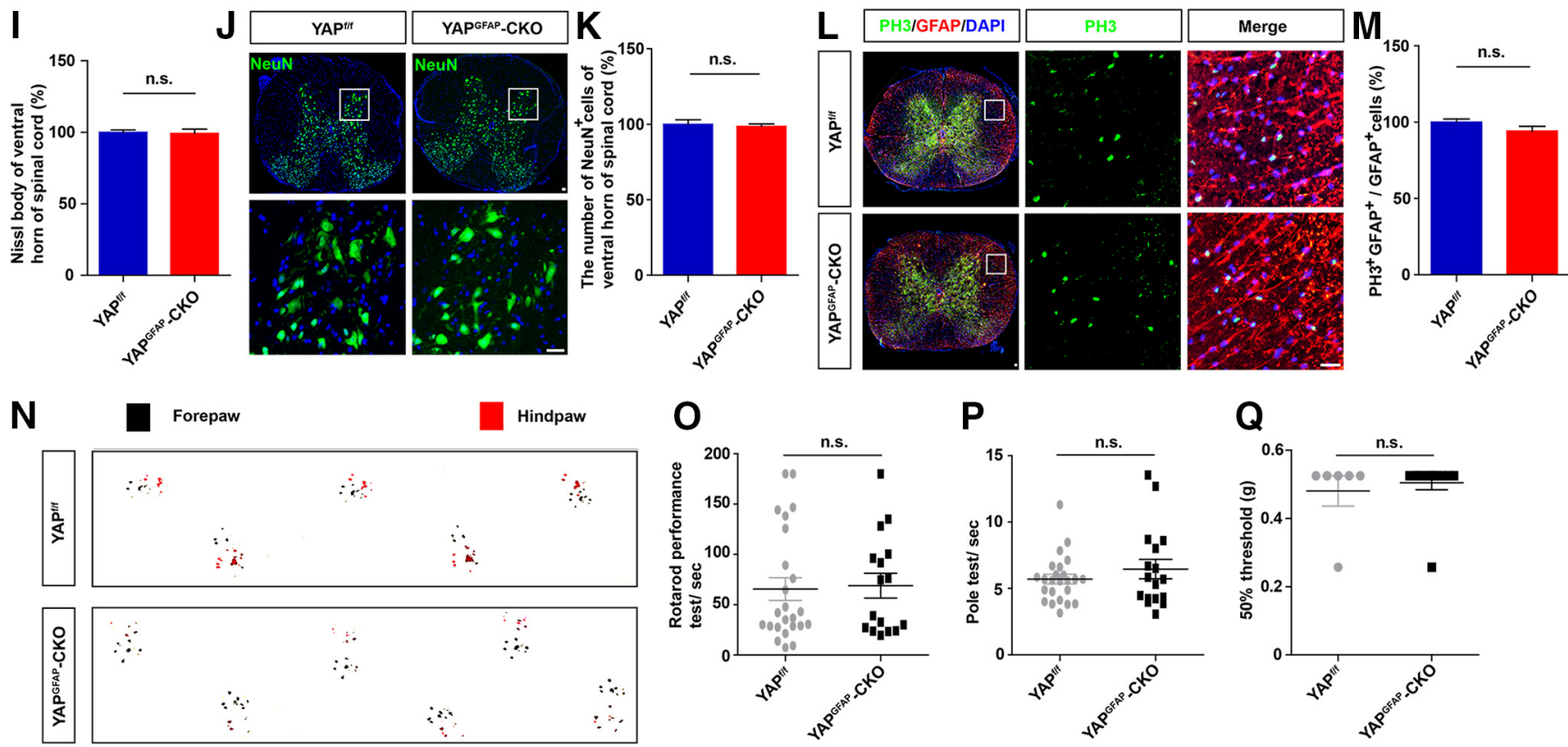

Figure 3. Normal development of spinal cords in yap ${ }^{G F A P}$-CKO mice. $A$, Western blot analysis of YAP expression in the cerebellum, hippocampus, cortex, and spinal cord of 2-month-old male ya ${ }^{f / f}$ and yap ${ }^{\text {GFAP }}$-CKO mice. B, Quantitative analysis of the relative YAP level as shown in $\boldsymbol{A}$ ( $n=3$ per group). C, Double immunostaining analysis of YAP (green) and GFAP (red) in spinal cords of 2-month-old male yap ${ }^{f / f}$ and yap ${ }^{G F A P}$-CKO mice. D, Western blot analysis of YAP expression in cultured yap ${ }^{+/+}$and yap ${ }^{-1-}$ astrocytes. E, Double immunostaining analysis of YAP (green) and GFAP (red) in cultured yap ${ }^{+/+}$and yap ${ }^{-/-}$astrocytes. $\boldsymbol{F}$, Quantitative analysis of astrocytic size as shown in $\boldsymbol{E}\left(n=19\right.$ per group). $\mathbf{G}$, Quantitative analysis of body weight of yap ${ }^{f / f}$ and yap ${ }^{G F A P}$-CKO mice at different developmental stages ( $n=3$ per group). $\boldsymbol{H}$, Typical Nissl staining images showing the ventral horn of spinal cords of 2-month-old male yap ${ }^{f / f}$ and yap ${ }^{G F A P}$-CKO mice. $\boldsymbol{I}$, Quantitative analysis of the number of Nissl staining-positive cells as shown in $\boldsymbol{H}$ ( $n=3$ per group).J, Immunostaining of NeuN (green) and DAPI (blue) in spinal cords of 2-month-old male yap ${ }^{f / f}$ and yap ${ }^{G F A P}$-CKO mice. $\boldsymbol{K}$, Quantitative analysis of the number of $\mathrm{NeuN}^{+}$cells as shown in $\boldsymbol{J}(n=3$ per group). $\boldsymbol{L}$, Double immunostaining analysis of PH3 (green) and GFAP (red) in spinal cords of 2-month-old male yap ${ }^{f / f}$ and yap ${ }^{G F A P}$-CKO mice. $M$, Quantitative analysis of the number of PH3 ${ }^{+} /$GFAP $^{+}$cells as shown in $\boldsymbol{L}\left(n=3\right.$ per group). $\boldsymbol{N}$, Representative footprint images of 2 -month-old male yap ${ }^{f / f}$ and yap ${ }^{G F A P}$-CKO mice in footprint behavioral assay as shown in Figure $6 B . \mathbf{O}, \boldsymbol{P}$, Quantitative analysis of rotarod performance $(\boldsymbol{O})$ and pole test $(\boldsymbol{P})$ in 2-month-old male yap ${ }^{f / f}$ and yap ${ }^{G F A P}$-CKO mice $(n=$ 24 for yap ${ }^{f / f}$ mice; $n=16$ for yap ${ }^{G F A P}$-CKO mice). $\mathbf{Q}$, Quantitative analysis of $50 \%$ threshold of von Frey hair test to the plantar surface hindpaw in 2 -month-old male yap ${ }^{f / f}$ and yap ${ }^{G F A P}$-CKO mice $(n=$ 6 per group). $\boldsymbol{C}, \boldsymbol{E}, \boldsymbol{H}, \boldsymbol{J}, \boldsymbol{L}$, Images of selected regions (white squares) are shown at higher magnification. $\boldsymbol{B}$, Quantitative data were analyzed using Student's paired two-tailed $t$ test. $\boldsymbol{F}, \boldsymbol{I}, \boldsymbol{K}, \boldsymbol{M}, \mathbf{0}, \boldsymbol{P}$, Q, Quantitative data were analyzed using Student's unpaired two-tailed $t$ test. G, Quantitative data were analyzed using two-way ANOVA with Bonferroni post tests. ${ }^{* * *} p<0.001$, compared with control. n.S., not significant. Data are mean \pm SEM. Scale bars, $20 \mu \mathrm{m}$.

results suggested that YAP was upregulated and activated in a Hippo pathway-dependent manner from $7 \mathrm{~d}$, especially at $14 \mathrm{~d}$ after SCI.

Moreover, to examine the spatial expression pattern of YAP in the spinal cord after SCI, we performed double immunostaining of YAP and cell markers, including GFAP (astrocytes marker), NeuN (neurons marker), and Ibal (microglia marker) in the mice spinal cords. In the uninjured spinal cords, YAP was detected in $\mathrm{GFAP}^{+}$astrocytes, but not in the
$\mathrm{NeuN}^{+}$neurons and $\mathrm{Ibal}^{+}$microglial cells (Figs. 1N, 2A,B). In addition, YAP was not expressed in primary cultured spinal cord neurons, but in MAP-2-negative cells (Fig. 2C). The YAP protein was upregulated and displayed the nuclear distribution in the GFAP ${ }^{+}$astrocytes at $14 \mathrm{~d}$ after SCI (Fig. $1 \mathrm{~N}, \mathrm{O}$ ). Together, these results indicated that YAP was upregulated and activated in the astrocytes in a Hippo pathway-dependent manner after SCI, implying that they may be involved in the formation of glial scars. 
A

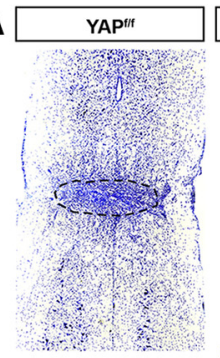

D

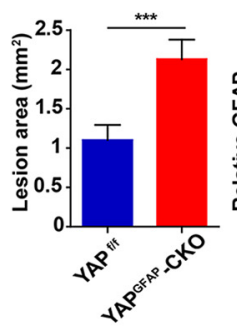

E
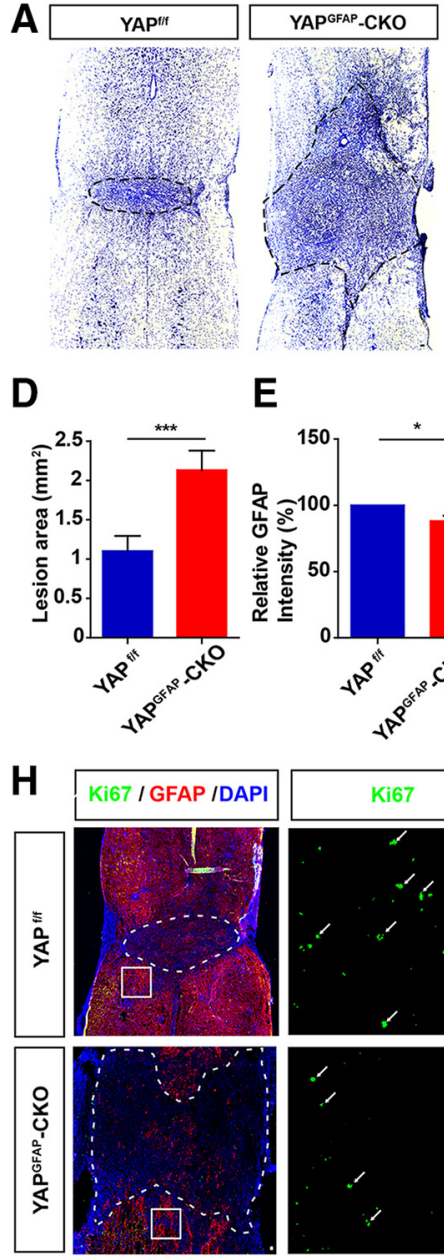

$\mathrm{J}$
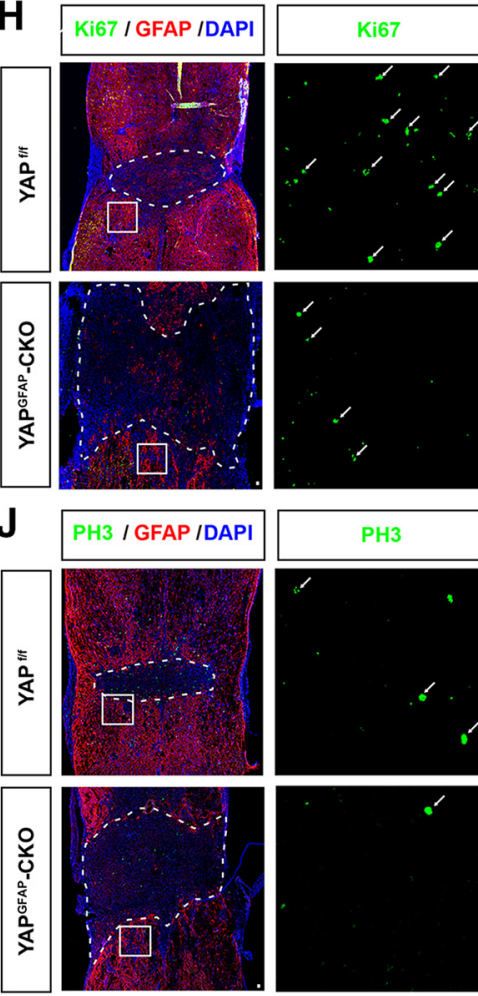
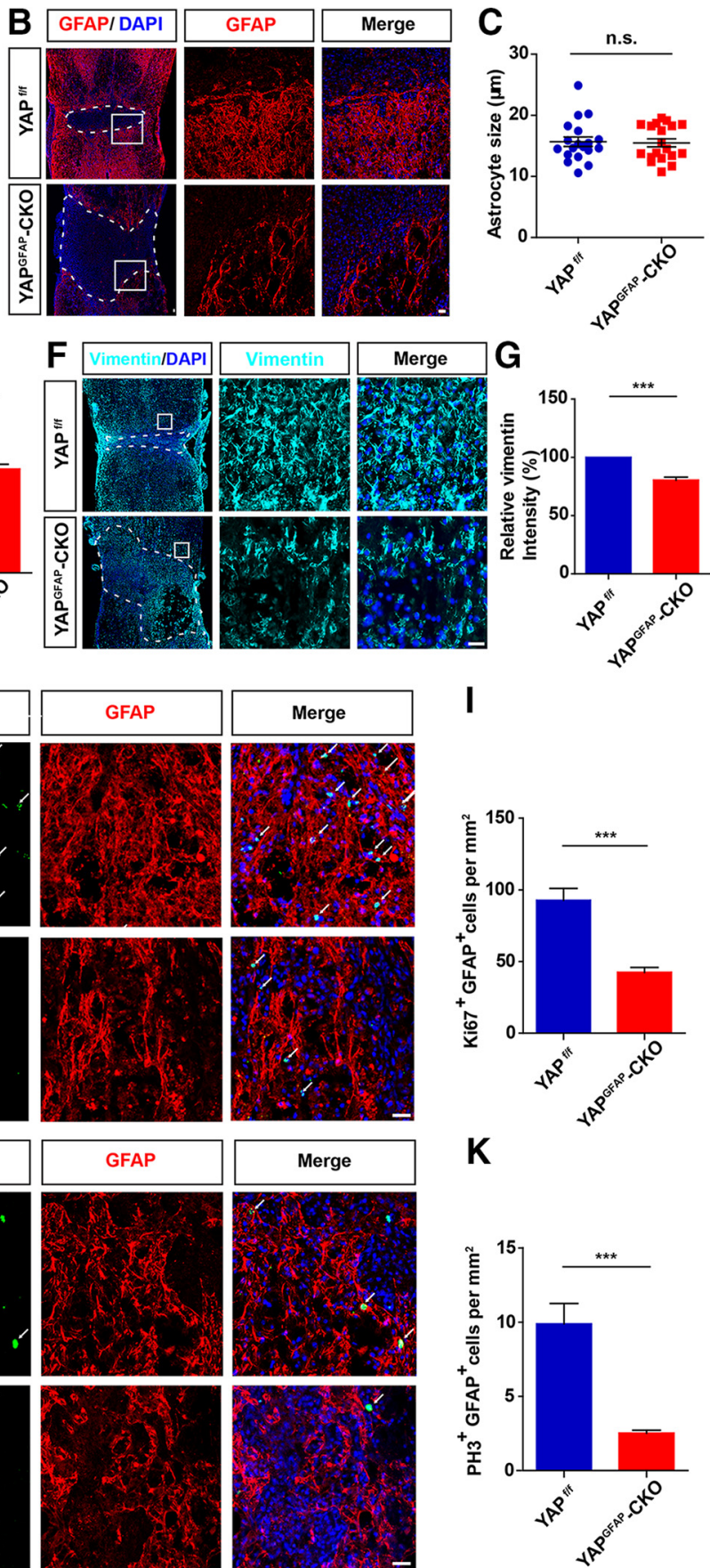

K

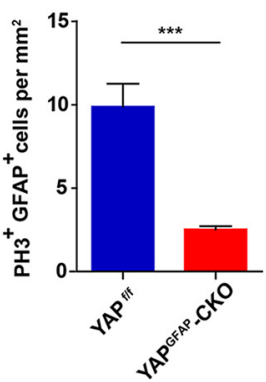

Figure 4. Conditional yap deletion in astrocytes impaired glial scar formation and increased the injury size due to the reduction of astrocytic proliferation after SCI. $\boldsymbol{A}$, Typical Niss staining images showing the spinal cords of 2-month-old male yap ${ }^{f / f}$ and yap ${ }^{G F A P}$-CKO mice at $14 \mathrm{~d}$ after SCl. B, Immunostaining of GFAP (red) in spinal cords of 2-month-old male yap ${ }^{f / f}$ and yap ${ }^{G F A P}$-CKO mice at $14 \mathrm{~d}$ after SCl. C, Quantitative analysis of astrocytic size as shown in $\boldsymbol{B}$ ( $n=5$ per group). $\boldsymbol{D}$, Quantitative analysis of lesioned size in spinal cords as shown in $\boldsymbol{B}$ ( $n=5$ per group). $\boldsymbol{E}$, Quantitative analysis of GFAP intensity in spinal cords as shown in $\boldsymbol{B}$ ( $n=5$ per group). $\boldsymbol{F}$, Immunostaining of vimentin (cyan) in spinal cords of 2-month-old male yap $^{f / f}$ and yap ${ }^{G F A P}$-CKO mice at $14 \mathrm{~d}$ after SCl. G, Quantitative analysis of vimentin intensity as shown in $\boldsymbol{F}$ ( $n=5$ per group). $\boldsymbol{H}$, Double immunostaining of Ki67 (green) and GFAP (red) in spinal cords of 2-month-old male yap ${ }^{f / f}$ and yap ${ }^{G F A P}$-CKO mice at $14 \mathrm{~d}$ after SCI. I, Quantitative analysis of the numbers of proliferating astrocytes by Ki67 ${ }^{+} /$GFAP $^{+}$colabeling within $1500 \mu \mathrm{m}$ of the injured spinal cords as shown in $\boldsymbol{H}\left(n=5\right.$ per group). $J$, Double immunostaining of PH3 (green) and GFAP (red) in spinal cords of 2-month-old male yap ${ }^{f / f}$ and yap ${ }^{G F A P}$-CKO mice at $14 \mathrm{~d}$ after $\mathrm{SCl}$. $\boldsymbol{K}$, Quantitative analysis of the numbers of proliferating astrocytes by PH3 ${ }^{+} / \mathrm{GFAP}^{+}$colabeling within $1500 \mu \mathrm{m}$ of the injured spinal cords as shown in $\boldsymbol{J}(n=5$ per group). White or black dashed lines indicate the injury sites. $\boldsymbol{B}, \boldsymbol{F}, \boldsymbol{H}, \boldsymbol{J}$, Images of selected regions (white squares) are shown at higher magnification. Student's unpaired two-tailed $t$ test: ${ }^{*} p<0.05,{ }^{* * *} p<0.001$, n.s., not significant. Data are mean \pm SEM. Scale bars, $20 \mu \mathrm{m}$.

Conditional yap deletion in astrocytes impaired the formation of glial scars and increased the injury size due to the reduction of astrocytic proliferation after SCI

The nuclear distribution of YAP in astrocytes at $14 \mathrm{~d}$ after SCI suggests that it plays a critical role in regulating the formation of glial scars after SCI. We generated a conditional yap deletion in the astrocytes in mice, $y a p^{G F A P}$-CKO mice, by crossing floxed yap allele ( a $^{f f f}$ ) with GFAP-Cre transgenic mice to test this hypothesis further. Yap was successfully knocked out in the spinal cords and the brain regions, such as cerebellum, hippocampus, and 
A

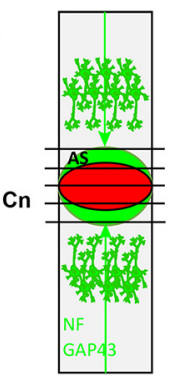

B
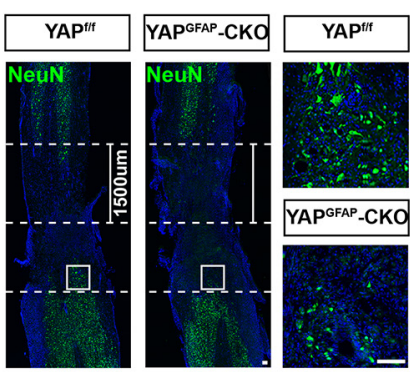

C
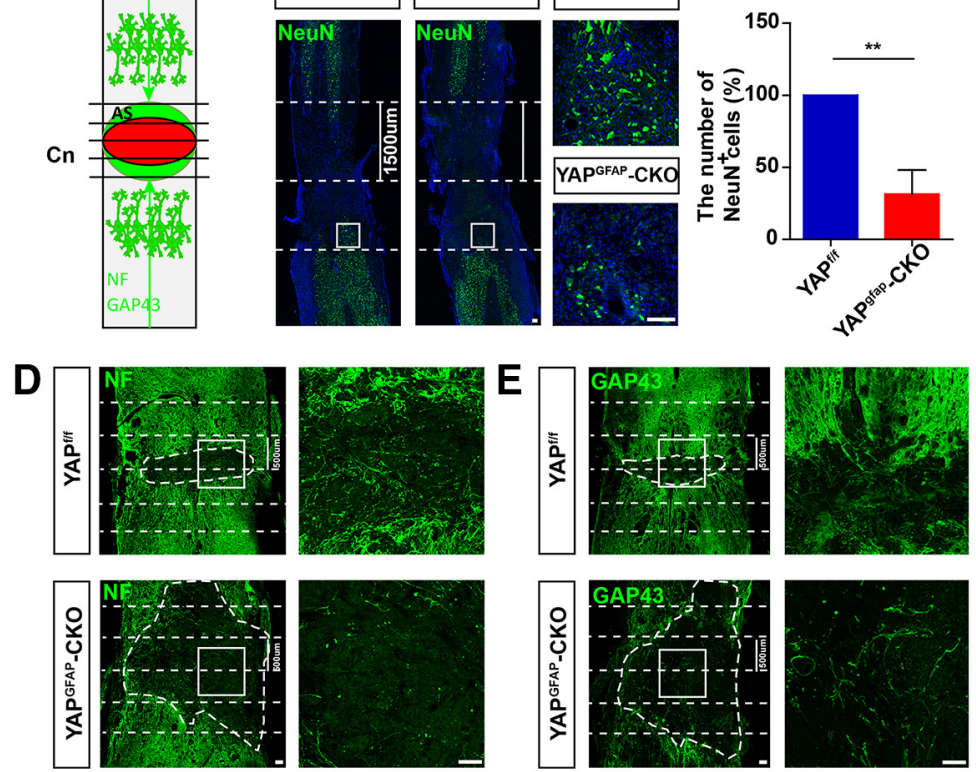

$\mathbf{F}$
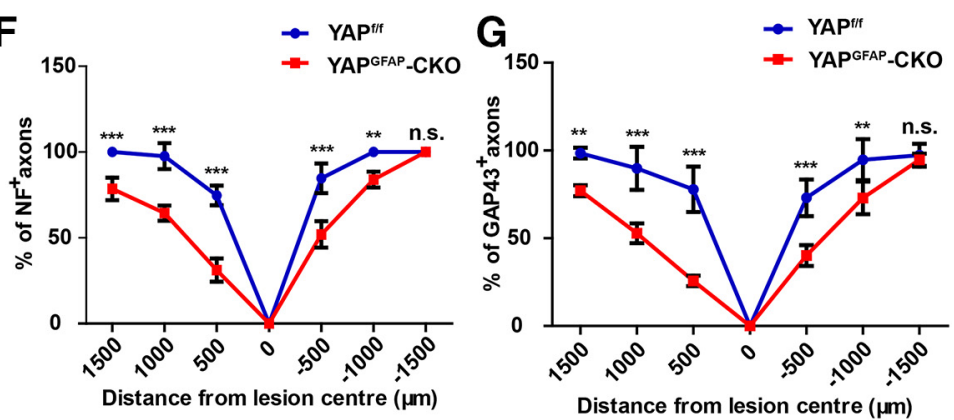

Figure 5. Conditional yap deletion in astrocytes inhibited neural regeneration after SCI. A, Scheme of analysis of NF or GAP43 positive axons after SCl. Horizontal view of lesion core and astrocytic scar (AS) after SCI. Intercepts of NF and GAP43 positive axons with lines drawn at various distances from lesion center $(\mathrm{Cn})$ were counted and expressed as a percentage of axons $1500 \mu \mathrm{m}$ proximal. $\boldsymbol{B}$, Immunostaining of NeuN (green) and DAPI (blue) in spinal cords of 2-month-old male yap ${ }^{f / f}$ and yap ${ }^{G F A P}$-CKO mice at $14 \mathrm{~d}$ after SCl. C, Quantitative analysis of the number of NeuN-positive cells in the distance lesion center of the spinal cords as shown in $\boldsymbol{B}\left(n=4\right.$ per group). $\boldsymbol{D}, \boldsymbol{E}$, Immunostaining of NF $(\boldsymbol{D})$ and GAP43 $(\boldsymbol{E})$ in spinal cords of 2-month-old male yap ${ }^{f / f}$ and yap ${ }^{G F A P}$-CKO mice at $14 \mathrm{~d}$ after $\mathrm{SCl}$. Dotted lines indicate lesion center $500 \mu \mathrm{m}$ on either side. $\boldsymbol{F}, \boldsymbol{G}$, Quantitative analysis of NF positive $(\boldsymbol{F})$ and GAP43 positive $(\boldsymbol{G})$ area at various distances from the $S C l$ lesion center as a percentage of the total area of axons present $1500 \mu \mathrm{m}$ proximal ( $n=5$ per group). Dotted lines indicate lesion center and $1500(\boldsymbol{B})$ or $500 \mu \mathrm{m}(\boldsymbol{D}, \boldsymbol{E})$ on either side. White dashed lines indicate the injury sites. $\boldsymbol{B}, \boldsymbol{D}, \boldsymbol{E}$, Images of selected regions (white squares) are shown at higher magnification. $\boldsymbol{C}$, Quantitative data were analyzed using Student's unpaired two-tailed $t$ test. $\boldsymbol{F}, \mathbf{G}$, Data were analyzed using two-way ANOVA with Bonferroni post tests. ${ }^{* *} p<0.01,{ }^{* * *} p<0.001$, n.S., not significant. Data are mean \pm SEM. Scale bars, $100 \mu \mathrm{m}$.

cortex, as well as in the primary cultured astrocytes (Fig. 3A-E). We found that there was no significant difference in the size between $y a p^{+/+}$and $y a p^{-/-}$astrocytes (Fig. $3 F$ ). Additionally, there was no significant difference in the body weight, neuronal number, and neuronal distribution in spinal cords between $y a p^{f / f}$ and $y a p^{G F A P}$-CKO mice (Fig. 3G-K). Moreover, the conditional KO yap did not significantly affect proliferation of the astrocytes in spinal cords (Fig. $3 L, M$ ). Behavior testings, including footprint, rotarod performance, pole test, and von Frey hair tests, showed that yap KO in astrocytes did not significantly affect the motor and mechanical sensory functions of mice (Fig. $3 \mathrm{~N}-\mathrm{Q}$ ). Together, these findings indicated that yap deletion in astrocytes did not affect the development of the spinal cords, motor and mechanical sensory functions.

The spinal cord samples were collected from yap fff and yap ${ }^{G F A P}$-CKO mice at $14 \mathrm{~d}$ after SCI since glial scars are considered mature at $14 \mathrm{~d}$ after SCI (Herrmann et al., 2008). Nissl staining showed that the lesion size of the injured spinal cord was significantly higher in the yap ${ }^{G F A P}$-CKO mice (Fig. $4 A, B, D, F)$. Immunostaining of the GFAP (glial scar maker) (Sofroniew, 2014; Chen et al., 2018b) showed that there was no significant difference in astrocyte size between yap ${ }^{f / f}$ mice and yap ${ }^{G F A P}$-CKO mice after SCI (Fig. 4C). However, the astrocytes at the lesion border formed a less compact scar border in yap ${ }^{G F A P}$-CKO mice at $14 \mathrm{~d}$ (Fig. $4 B, F$ ) and the fluorescence intensity of GFAP (Fig. $4 E$ ) or vimentin (glial scar maker) (Fig. 4G) around the lesion sites was significantly lower in $y a p^{G F A P}$-CKO mice than in the control group. Since previous findings indicated that the closer to the lesion area, the higher the number of the proliferating astrocytes at $14 \mathrm{~d}$ after SCI (Wanner et al., 2013), we examined whether the reduction of glia scars in yap ${ }^{G F A P}$-CKO mice was caused by the decrease of the proliferation of astrocytes by yap deletion. The GFAP were colabeled with Ki67 or $\mathrm{PH} 3$ (cell proliferation markers) for the identification of proliferation astrocytes (Frik et al., 2018). Compared with the control mice, both the number of $\mathrm{Ki}^{+} 7^{+} \mathrm{GFAP}^{+}$cells (Fig. 4I) and $\mathrm{PH}^{+} / \mathrm{GFAP}^{+}$cells (Fig. $4 \mathrm{~K}$ ) around the lesion sites were significantly lower in the $y a p^{G F A P}$-CKO mice at $14 \mathrm{~d}$ after SCI (Fig. $4 H-K$ ). These results together suggested that yap deletion in the astrocytes impaired glial scar formation due to the reduction of astrocytic proliferation after SCI, resulting in injury size increasement.

\section{Conditional yap deletion in astrocytes} inhibited neural regeneration after SCI Following SCI, the mature glial scar persists over long periods and limits or aids axon regeneration (Yiu and He, 2006; Anderson et al., 2016). Therefore, we examined whether a reduction of glial scars affected neural regeneration in $y a p^{G F A P}$-CKO mice after SCI. We analyzed the status of axon by its features constituting of the number of neurons near the lesion sites and the axonal regeneration (Fig. 5A). Immunohistochemical analysis of NeuN showed that there was a decrease in the number of neurons in the distant lesion center in the $\mathrm{KO}$ mice within $1500 \mu \mathrm{m}$ (Fig. 5B,C). The neurofilament positive $\left(\mathrm{NF}^{+}\right)$and growth-associated protein- 43 positive $\left(\mathrm{GAP}^{+} 3^{+}\right)$axons are used in the analysis of axonal regeneration (Kaneko et al., 2006; Chen et al., 2019; Ren et al., 2019). NF forms the framework of nerve cells and participates in axonal transport (Hoffman and Lasek, 1975; Brown et al., 2005; Yuan et al., 2017), whereas GAP43 functions in neurite formation, regeneration, and plasticity (Kaneko et al., 2006). Therefore, we used NF and GAP43 as regeneration axon markers. A significantly smaller number of $\mathrm{NF}^{+}$axons (Fig. $5 D, F$ ) as well as GAP $43^{+}$axons (Fig. $5 E, G$ ) were observed within the lesion site in $y a p^{G F A P}-\mathrm{CKO}$ mice at $14 \mathrm{~d}$ after $\mathrm{SCI}$, compared with the 
control mice. These results suggested that yap $\mathrm{KO}$ in astrocyte inhibited axonal regeneration.

\section{Conditional yap deletion in astrocytes inhibited the behavioral recovery after SCI}

We next examined whether the recovery of motor function and mechanical sensory function were affected by yap deletion after SCI. The behavior status analysis constituted the following: footprint analysis, open-field locomotor task, rotarod performance, and von Frey hair test. The behavioral recovery was significantly reduced in the $y a p^{G F A P}$-CKO mice in footprint assays from 14 and $28 \mathrm{~d}$ after SCI, compared with the control mice (Fig. $6 A-C)$. Additionally, there was a significant difference in open field score from 21 and $28 \mathrm{~d}$ after SCI (Fig. 6D). However, there were no significant differences in rotarod performance (Fig. $6 E$ ) and mechanical sensory functions (Fig. 6F) between the $y a p^{f / f}$ and $y a p^{G F A P}$-CKO mice. Together, these results suggested that $\mathrm{KO}$ astrocytic yap in mice caused a defect in the behavioral recovery of mice after SCI.

\section{bFGF was upregulated, activated YAP signaling, and promoted the formation of glial scars after SCI}

Since bFGF is upregulated after SCI and promotes the proliferation of astrocytes (Koshinaga et al., 1993; Follesa et al., 1994; Mocchetti et al., 1996; Zai et al., 2005), we investigated whether the bFGF as an upstream molecule of YAP that promoted astrocytic proliferation. We found that $b F G F$ mRNA was significantly upregulated after SCI, particularly at $14 \mathrm{~d}$ (Fig. 7A). Treatment of the mice through bFGF injection significantly promoted the motor recovery in the footprint analysis at $14 \mathrm{~d}$ after SCI (Fig. $7 \mathrm{~B}, \mathrm{C}$ ). However, there was no significant change in the mechanical sensory functions of the mice, compared with WT mice following bFGF treatment (Fig. 7D). Additionally, the lesion size of injured spinal cord was significantly decreased after bFGF treatment (Fig. $7 E, F)$, and the expression level of GFAP was significantly increased after bFGF treatment (Fig. $7 E$ ). These results suggested that bFGF was upregulated and promoted the formation of glial scars after SCI. The Western blot analysis revealed that bFGF treatment indeed activated YAP and upregulated vimentin (glial scar marker) after SCI (Fig. 7G-J). Together, these results suggested that bFGF was upregulated, activated YAP signaling, and promoted the formation of glial scars after SCI.

\section{bFGF promoted the proliferation of cultured astrocytes by activating YAP}

We next used cultured astrocytes to investigate the molecular mechanism how bFGF activates YAP signaling and then promotes astrocyte proliferation. As shown in Figure $8 A-C$, YAP expression was significantly increased with bFGF treatment in a time-dependent manner, whereas p-YAP and p-YAP/YAP significantly decreased in cultured astrocytes. The Hippo pathway kinase proteins, including LATS1 (Fig. 8A,E) and MST1 (Fig. $8 A, G)$, were significantly upregulated after bFGF treatment. On the contrary, the relative ratios of p-LATS1/LATS1 (Fig. 8A,D) and p-MST1/2/MST1 (Fig. 8A,F) were significantly decreased after bFGF treatment. These results suggested that YAP was upregulated and activated in a Hippo pathway-dependent manner after bFGF treatment. Additionally, immunostaining assays revealed that bFGF treatment enhanced the nuclear translocation of YAP (Fig. 8H). Western blot analysis of an incubation of astrocytes with $\mathrm{CHX}$, an inhibitor of protein synthesis, at different time points revealed that bFGF treatment did not significantly increase the stability of the YAP protein (Fig. 8I,J). Additionally, the immunostaining of Ki67 (Fig. $8 K, L$ ) or PH3 (Fig. $8 M, N$ ) with GFAP showed that bFGF treatment significantly promoted the proliferation of astrocytes (Fig. $8 K-N$ ), compared with control treatment. Together, these results suggested that bFGF treatment upregulated and activated YAP, and promoted the proliferation of cultured astrocytes.

We next examined whether YAP was required for bFGFinduced proliferation of astrocytes. $y a p^{+/+}$and yap-deleted astrocytes $\left(y a p^{-/-}\right)$were cultured from $y a p^{f / f}$ and $y a p^{G F A P}-\mathrm{CKO}$ mice, respectively, and then treated with bFGF. The immunostaining of Ki67 (Fig. 9A,B) or PH3 (Fig. 9C,D) revealed that bFGF treatment significantly promoted proliferation of $y a p^{+/+}$ astrocytes; however, bFGF treatment failed to induce the proliferation of yap-deleted astrocytes (Fig. 9A-D). These results suggested that yap was required for the bFGF-induced proliferation of astrocytes.

Since bFGF is secreted by astrocytes following SCI injury (Koshinaga et al., 1993; Follesa et al., 1994; Mocchetti et al., 1996; Zai et al., 2005) and bFGF is a target gene of YAP in fallopian tube secretory epithelial cells (Hua et al., 2016), we next examined whether $b F G F$ was a target gene of YAP in astrocytes. We sequenced the mRNA of $y a p^{+/+}$and $y a p^{-1-}$ astrocytes and analyzed the change of growth factor family members (Fig. 9E,F). Subsequently, the mRNA of the fibroblast growth factor family members, including bFGF (FGF2), were not significantly changed in $y a p^{-/-}$astrocytes, compared with $y a p^{+/+}$astrocytes 

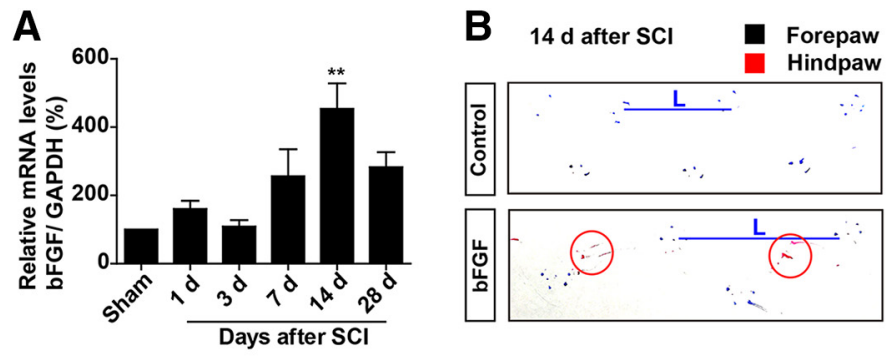

D
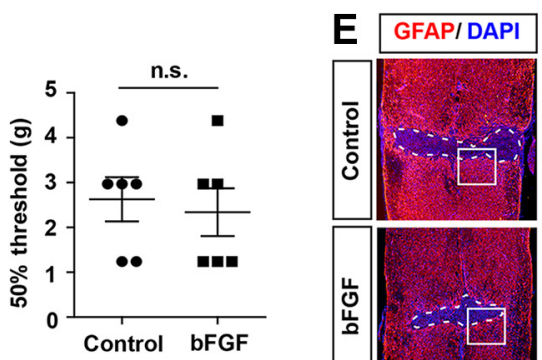
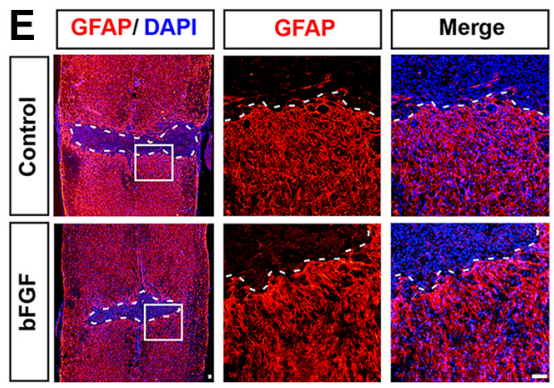

G

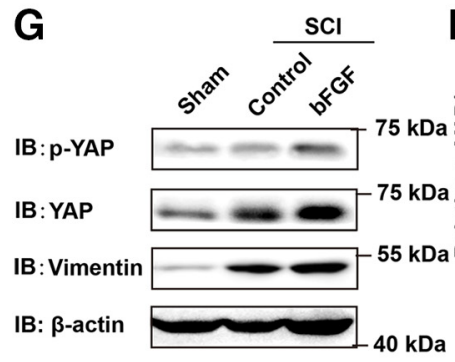

H

I

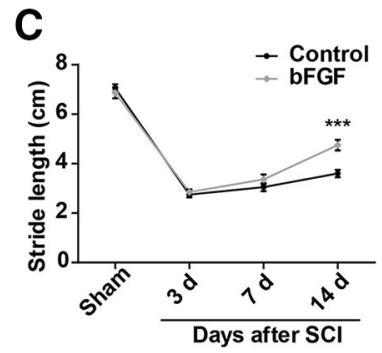

F

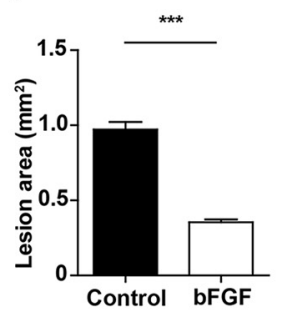

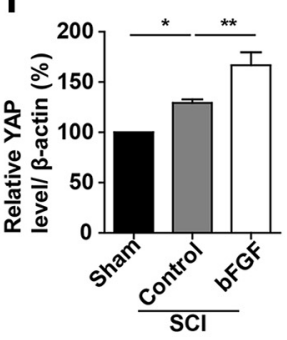

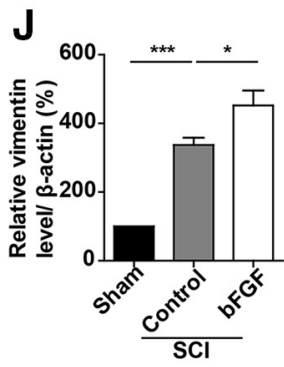

Figure 7. bFGF was upregulated, activated YAP signaling, and promoted the formation of glial scars after SCI. $A$, Real-time PCR analysis showed the relative mRNA level of $b F G F$ in spinal cords of 2-month-old male mice at different stages after $\mathrm{SCl}$ ( $n=3$ per group). $\boldsymbol{B}$, Representative footprint images of control and bFGF-treated mice at $14 \mathrm{~d}$ after $S C \mathrm{Cl}$. $\boldsymbol{C}$, Quantitative footprint analysis of stride length in uninjured mice (Sham mice), control, and bFGF-treated mice after SCI ( $n=6$ per group). $D$, Quantitative analysis of $50 \%$ threshold of von Frey hair test to the plantar surface hindpaw in control and bFGF-treated mice after $\mathrm{SCl}(n=6$ per group). $\boldsymbol{E}$, Immunostaining of GFAP (red) in spinal cords of control and bFGF-treated mice at $14 \mathrm{~d}$ after $\mathrm{SCl}$. $\boldsymbol{F}$, Quantitative analysis of lesioned size in spinal cords as shown in $\boldsymbol{E}$. G, Western blot analysis of p-YAP, YAP, and vimentin expression in spinal cords of control and bFGF-treated mice $14 \mathrm{~d}$ after SCI. $\boldsymbol{H}-\boldsymbol{J}$, Quantitative analysis of p-YAP/YAP $(\boldsymbol{H})$, YAP $(\boldsymbol{I})$, and vimentin $(\boldsymbol{J})$ protein levels as shown in $\boldsymbol{G}(n=3$ per group). White dashed lines indicate the injury sites. $\boldsymbol{E}$, Images of selected regions (white squares) are shown at higher magnification. C, Quantitative data were analyzed using two-way ANOVA with Bonferroni post tests. D, F, Data were analyzed using Student's unpaired two-tailed $t$ test. $\boldsymbol{H}-\boldsymbol{J}$, Quantitative data were analyzed using one-way ANOVA with Bonferroni's multiple-comparison test. ${ }^{*} p<0.05,{ }^{* *} p<0.01,{ }^{* * *} p<0.001$, n.S., not significant. Data are mean \pm SEM. Scale bars, $20 \mu$ m.

(Fig. 9F). qPCR confirmed that there was no significant difference in the relative mRNA levels of $b F G F$ between $y a p^{+/+}$and yap ${ }^{-1-}$ astrocytes (Fig. 9G). These results implied that YAP was required for bFGF-induced proliferation of astrocytes and not the transcription of $b F G F$ in astrocytes.

\section{RhoA pathway was required for bFGF-induced activation of YAP and proliferation of astrocytes}

Since the RhoA pathway is an important upstream signal of YAP (Huang et al., 2016c; He et al., 2019) and downstream signal of FGF receptor pathway (Ge et al., 2016; Z. G. Wang et al., 2016), we examined whether RhoA pathway as bFGF downstream molecule that regulates YAP activity. We found that Y-27632 (a specific Rho associated kinase inhibitor that inhibits the RhoA pathway) inhibited the bFGF-induced activation of YAP (Fig. $10 A-C$ ) and astrocytic proliferation (Fig. $10 D, E$ ). This suggested that bFGF activated YAP through the RhoA pathway. Meanwhile, as a positive downstream signaling control of bFGF (Hua et al., 2016), bFGF also upregulated p-Akt and the ratio of p-Akt/total Akt, which indicated that bFGF also activated the Akt pathway in our treatment system (Fig. $10 F, G$ ). These results suggest that RhoA pathway was required for bFGF-induced activation of YAP and proliferation of astrocytes.
YAP promoted the proliferation of astrocytes through negatively controlling nuclear distribution of $\mathrm{p} 27^{\text {Kip1 }}$

How does YAP regulate bFGF-induced proliferation of astrocytes and participate in the formation of glial scars? Cell proliferation is associated with the cell cycle; for instance, p2 $7^{\mathrm{Kip} 1}$, a cyclin-dependent kinase (CDK) enzyme inhibitor, serves as a major negative regulator in cell proliferation in various cells (Nakayama et al., 2004; Jang et al., 2017). The expression level of $\mathrm{p} 27^{\mathrm{Kip} 1}$ protein was significantly increased after SCI, whereas yap deletion significantly reduced the increasing level of $\mathrm{p} 27^{\mathrm{Kip} 1}$ protein expression (Fig. $11 A, B$ ). Similarly, yap deletion inhibited the increasing expression of $\mathrm{p} 27^{\mathrm{Kip} 1}$ protein in bFGF-induced astrocytes (Fig. 11C,D). These results suggested that YAP promoted the expression of $\mathrm{p} 27^{\mathrm{Kip} 1}$ in astrocytes by SCI or bFGF treatment. Since YAP regulates the proliferation of several cells through p $27^{\mathrm{Kip} 1}$ and the subcellular distribution of $\mathrm{p} 27^{\mathrm{Kip} 1}$ is critical to the proliferation of cells (Shen et al., 2008, 2019; Li et al., 2009; Ishida et al., 2015; Kim and Kang, 2018), we next examined whether YAP promoted the proliferation of astrocytes by regulating the subcellular distribution of $\mathrm{p} 27^{\mathrm{Kip} 1}$. The bFGF treatment significantly increased the cytoplasm distribution of $\mathrm{p} 27^{\mathrm{Kip} 1}$ and reduced the nucleus/cytoplasm ratio of $\mathrm{p} 27^{\mathrm{Kip} 1}$, whereas yap deletion significantly increased the nucleus/cytoplasm ratio of $\mathrm{p} 27^{\mathrm{Kip} 1}$ and failed to reduce the nucleus/cytoplasm ratio of 

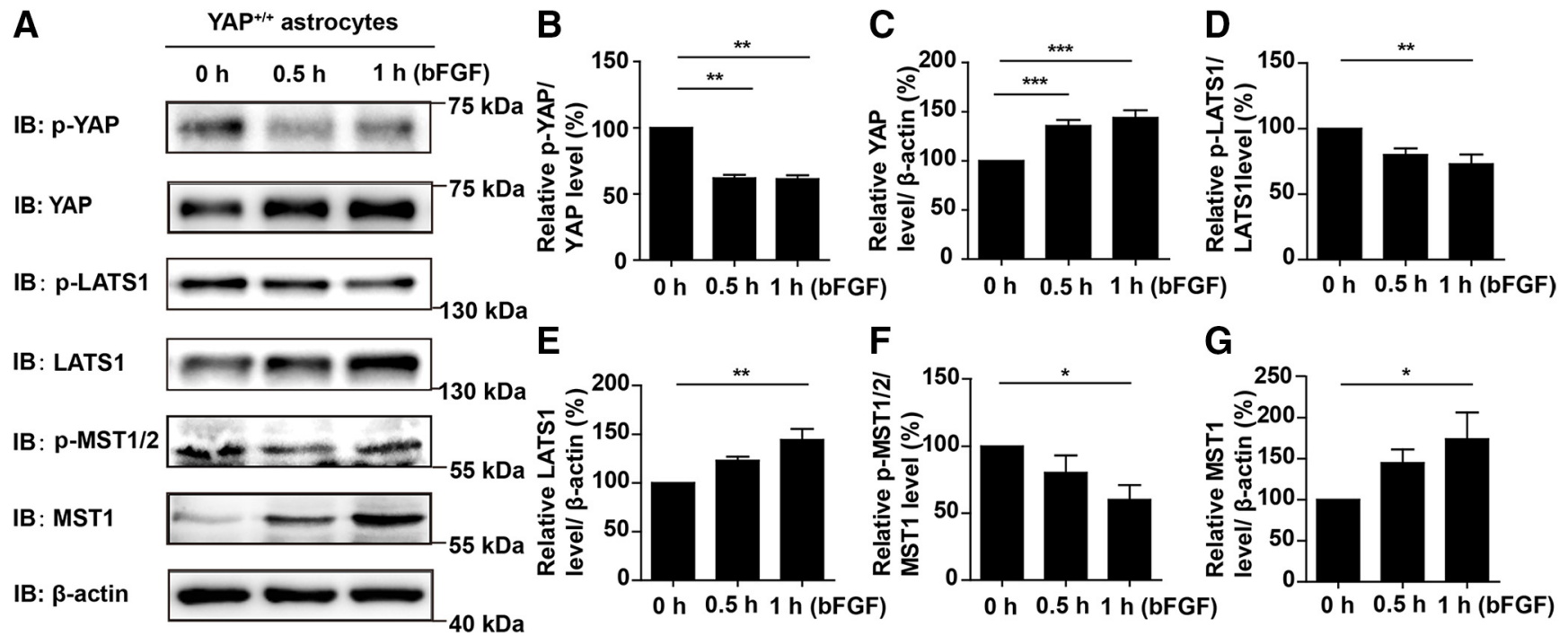

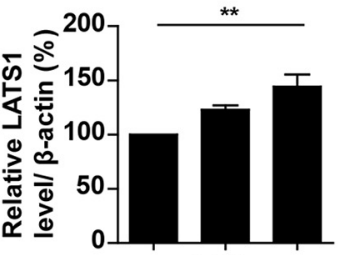

$0 \mathrm{~h} 0.5 \mathrm{~h} 1 \mathrm{~h}$ (bFGF)
$F$

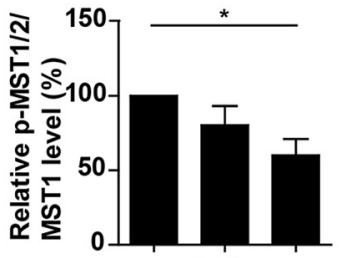

$0 \mathrm{~h} \quad 0.5 \mathrm{~h} 1 \mathrm{~h}$ (bFGF)
G

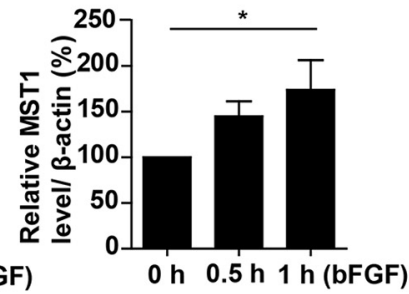

H

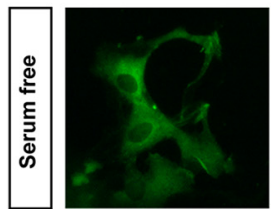

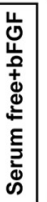
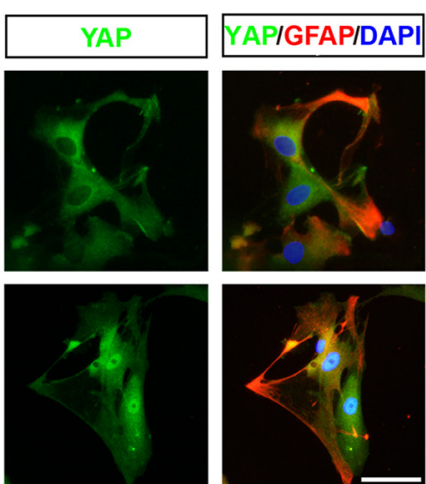

$\mathbf{L}$
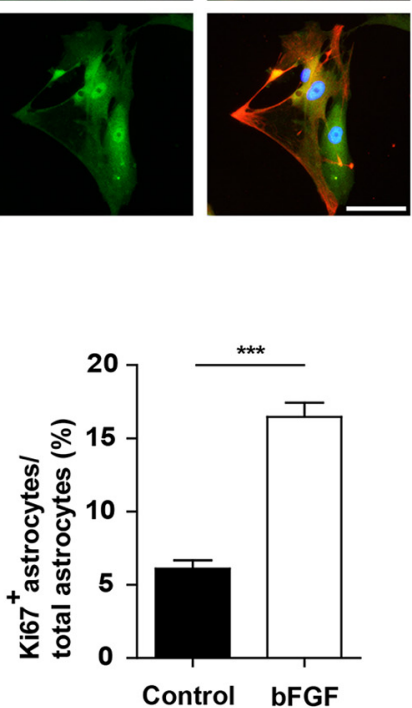

I

IB : YAP

IB: $\beta$-actin

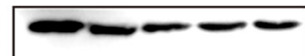

J

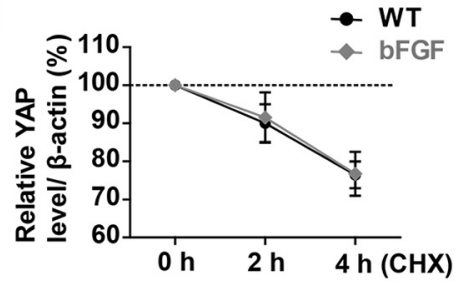

M

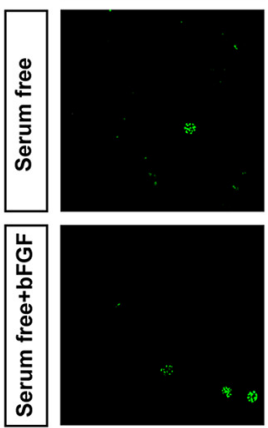

CHX CHX+bFGF

oh 2 h 4 h 2 h 4 h

$0 \mathrm{~h} \quad 2 \mathrm{~h} \quad 4 \mathrm{~h}(\mathrm{CHX})$

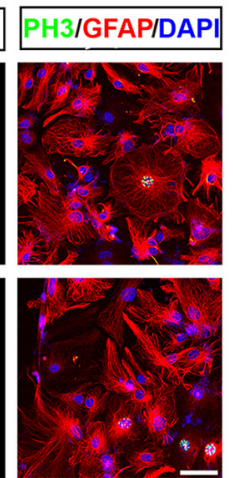

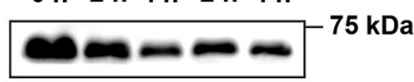

40 kDa
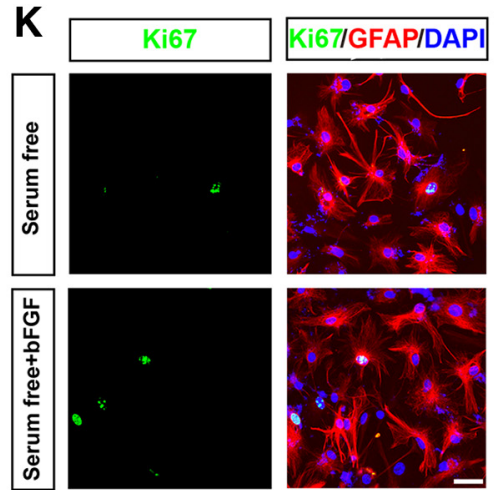

$\mathbf{N}$

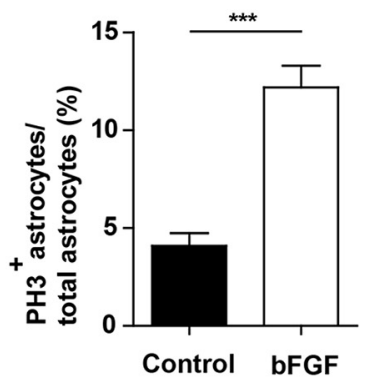

Figure 8. bFGF activated YAP signaling in a Hippo kinase-dependent manner and promoted the proliferation of cultured astrocytes. $\boldsymbol{A}$, Western blot analysis of $\mathrm{p}$-YAP, YAP, p-LATS1, LATS1, p-MST1/2, and MST1 expression in WT astrocytes treated with bFGF (100 ng/ml) at indicated time points. $\boldsymbol{B}-\boldsymbol{G}$, Quantitative analysis of the relative levels of $\mathrm{p}$-YAP/YAP $(\boldsymbol{B})$, YAP $(\boldsymbol{C})$, p-LATS1/LATS1 ( $\boldsymbol{D})$, LATS1 (E), p-MST1/2/MST1 ( $\boldsymbol{F}$ ), and MST1 (G) as shown in $\boldsymbol{A}(n=5$ per group). $\boldsymbol{H}$, Double immunostaining analysis of YAP (green) and GFAP (red) in WT astrocytes treated with bFGF $(100 \mathrm{ng} / \mathrm{ml})$ for $1 \mathrm{~h}$. I, Western blot showing YAP level in WT astrocytes treated with CHX (100 $\mu \mathrm{M})$ plus bFGF at indicated time points. $J$, Quantitative analysis of the relative level of YAP as shown in $\boldsymbol{I}(n=5$ per group). $\boldsymbol{K}, \boldsymbol{M}$, Double immunostaining analysis of Ki67 (green) and GFAP (red) $(\boldsymbol{K})$, or PH3 (green) and GFAP (red) ( $\boldsymbol{M}$ ) in WT astrocytes treated with bFGF (100 ng/ml). $\boldsymbol{L}, \boldsymbol{N}$, Quantitative analysis of the percentages of Ki67 ${ }^{+} / \mathrm{GFAP}^{+}(\boldsymbol{L})$ or PH $3^{+} / \mathrm{GFAP}^{+}(\boldsymbol{N})$ proliferating astrocytes over total astrocytes as shown in $\boldsymbol{K}$ or $\boldsymbol{M}(n=$ 6 per group). $\boldsymbol{B}-\mathbf{G}$, Quantitative data were analyzed using one-way ANOVA with Dunnett's multiple-comparison test. $J$, Quantitative data were analyzed using two-way ANOVA with Bonferroni post tests. $\boldsymbol{L}, \boldsymbol{M}$, Quantitative data were analyzed using Student's unpaired two-tailed $t$ test. ${ }^{*} p<0.05,{ }^{* *} p<0.01,{ }^{* * *} p<0.001$. Data are mean \pm SEM. Scale bars, $20 \mu \mathrm{m}$.

p27 ${ }^{\text {Kip } 1}$ induced by bFGF (Fig. 11 E,F). Additionally, immunostaining analysis of $\mathrm{p} 27^{\mathrm{Kip} 1}$ revealed that the deletion of yap in astrocytes significantly increased the nucleus/cytoplasm ratio of p27 Kip 1 , compared with $\mathrm{yap}^{+/+}$astrocytes (Fig. 11G,H). Finally, the overexpression of $\mathrm{p} 27^{\mathrm{Kip} 1}$-EGFP in WT astrocytes significantly decreased the bFGF-induced proliferation of astrocytes, compared with the EGFP control group (Fig. 11 I,J). Additionally, yap deletion significantly increased the nucleus/cytoplasm ratio of the $\mathrm{p} 27^{\mathrm{Kip} 1}$ in astrocytes transfected with EGFP-p27 Kip1 constructs, compared with the yap ${ }^{+/+}$astrocytes (Fig. $11 K, L$ ). These findings indicated that YAP promoted the astrocytic proliferation through negatively controlling nuclear distribution of $\mathrm{p} 27^{\mathrm{Kip} 1}$. 
A
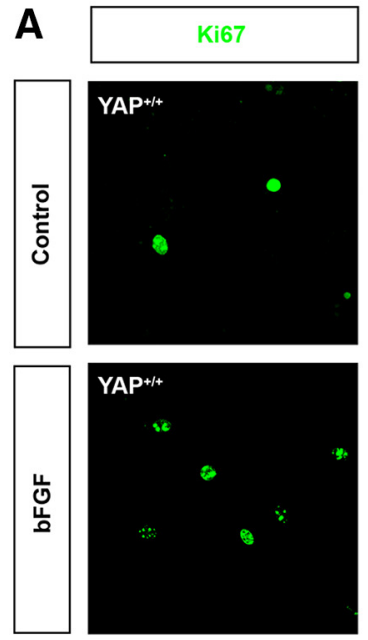

C
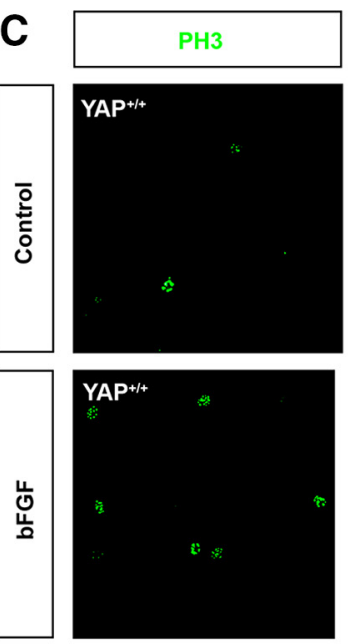

E

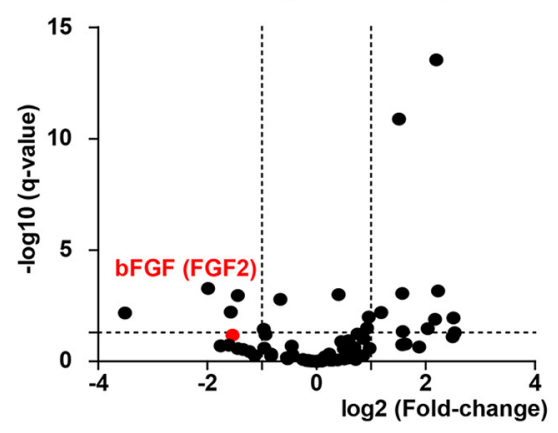

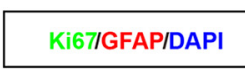
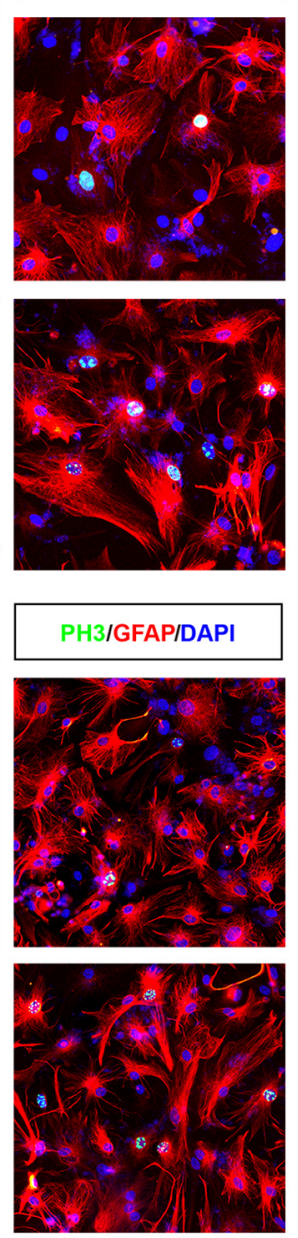
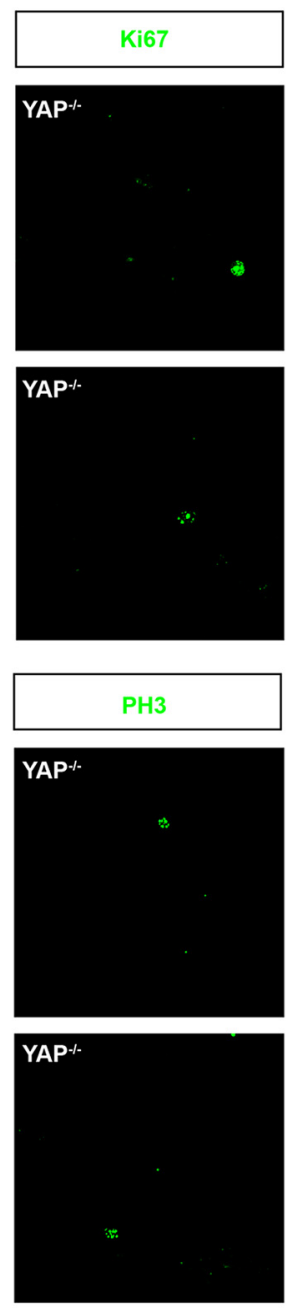

$F$

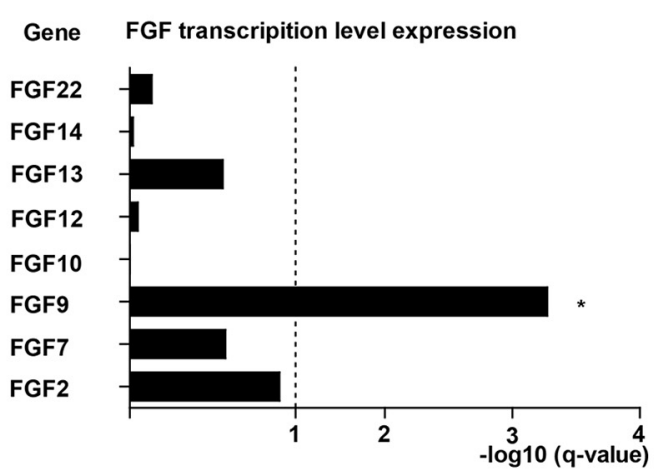

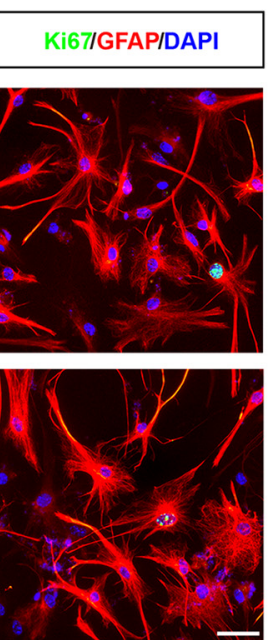

B
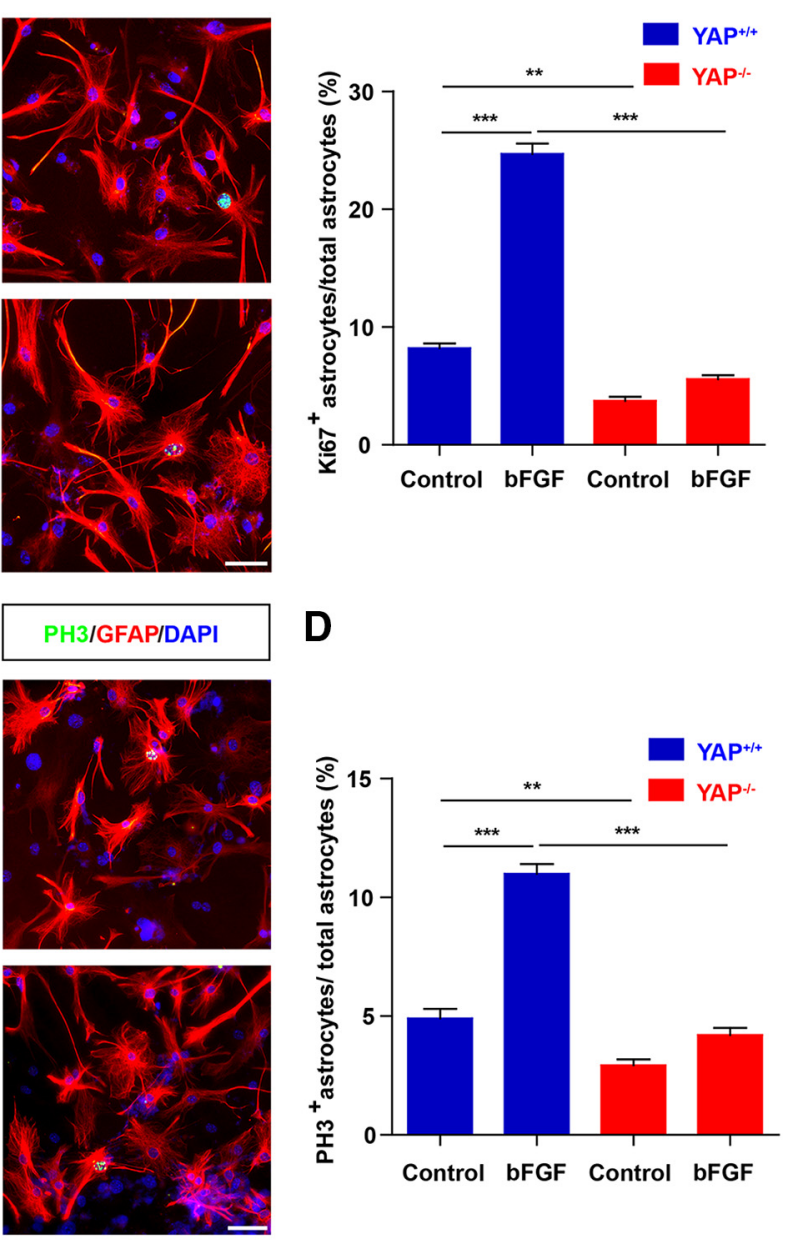

G

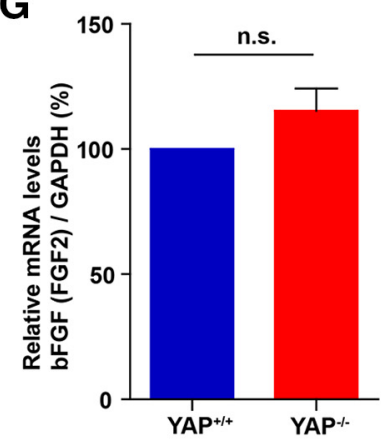

Figure 9. YAP was required for bFGF-induced proliferation of astrocytes, but not the transcription of $b F G F$ mRNA. $A, C$, Double immunostaining analysis of Ki67 (green) and GFAP (red) (A) or PH3 (green) and GFAP (red) $(\boldsymbol{C})$ in yap ${ }^{+/+}$and yap ${ }^{-/-}$astrocytes treated with bFGF $(100 \mathrm{ng} / \mathrm{ml})$ for $1 \mathrm{~h} . \boldsymbol{B}, \boldsymbol{D}$, Quantitative analysis of the percentages of Ki67 ${ }^{+} / \mathrm{GFAP}^{+}(\boldsymbol{B})$ or PH3 ${ }^{+} / \mathrm{GFAP}^{+}(\boldsymbol{D})$ proliferating astrocytes over total astrocytes as shown in $\boldsymbol{A}\left(n=8\right.$ per group). $\boldsymbol{E}$, The volcano plot of differential mRNAs of growth factor family sequenced in yap ${ }^{+/+}$and yap ${ }^{-/-}$astrocytes. $\boldsymbol{F}$, Histogram of $F G F$ family mRNAs sequenced in $y a p^{+/+}$and yap ${ }^{-/-}$astrocytes. G, Real-time PCR analysis showed the relative mRNA level of $b F G F$ in yap $p^{+/+}$and yap ${ }^{-/-}$astrocytes $(n=3$ per group). $\boldsymbol{B}, \mathbf{D}$, Quantitative data were analyzed using one-way ANOVA with Bonferroni's multiple-comparison test. G, Quantitative data were analyzed using Student's paired two-tailed $t$ test. ${ }^{*} p<$ $0.05,{ }^{* *} p<0.01,{ }^{* * *} p<0.001$, n.S., not significant. Data are mean \pm SEM. Scale bars, $20 \mu \mathrm{m}$.

YAP promoted bFGF-induced proliferation of astrocytes through negatively controlling nuclear distribution of p27 ${ }^{\mathrm{Kip} 1}$ mediated by CRM1

How does YAP negatively regulate the nuclear distribution of p2 $7^{\text {Kipl}}$ ? We sequenced mRNA of $y a p^{+/+}$and $y a p^{-/-}$astrocytes, and the regulatory proteins of $\mathrm{p} 27^{\mathrm{Kip} 1}$, including $C R M 1, C D K 5$, and SGK1 (Fig. 12A,B). The CRM1 mRNA was significantly decreased in yap-deleted astrocytes. qPCR confirmed that the
CRM1 mRNA was significant downregulation between $y a p^{+/+}$ and $y \mathrm{ap}^{-1-}$ astrocytes (Fig. 12C). Previous studies have shown that CRM1 promotes nuclear export of $\mathrm{p} 27^{\mathrm{Kipl}}$ (Hnit et al., 2015). Therefore, we examined the protein levels of CRM1 in spinal cords of $y a p^{f / f}$ and $y a p^{G F A P}$-CKO mice at $14 \mathrm{~d}$ after SCI. The expression level of CRM1 protein was increased after SCI, and yap deletion inhibited the increasing expression of CRM1 protein after SCI (Fig. 12D,E). Similarly, there were signifi- 


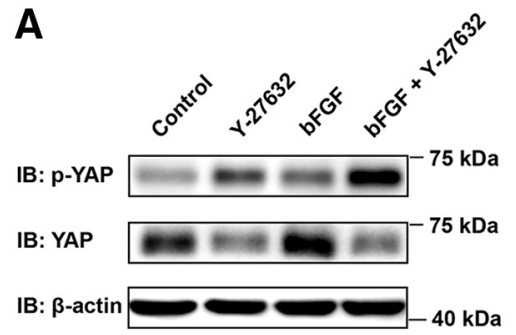

B
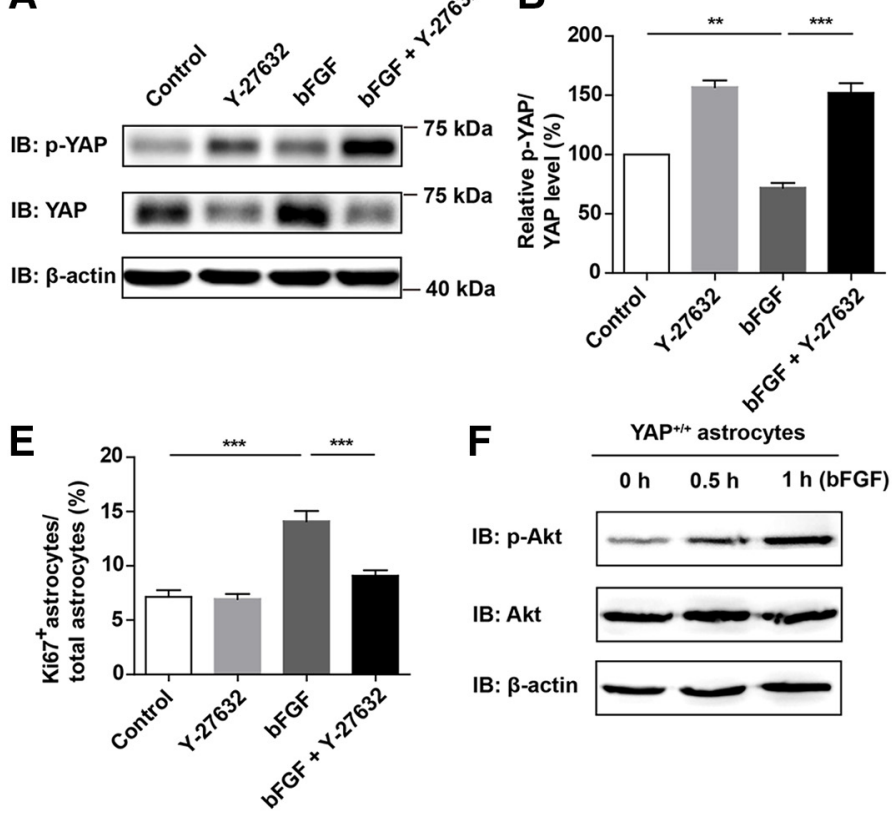

$\mathbf{F}$

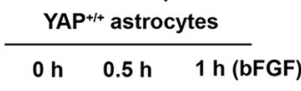

IB: p-Akt

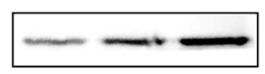

IB: Akt

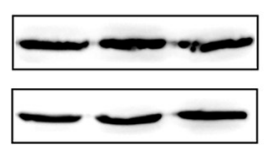

C
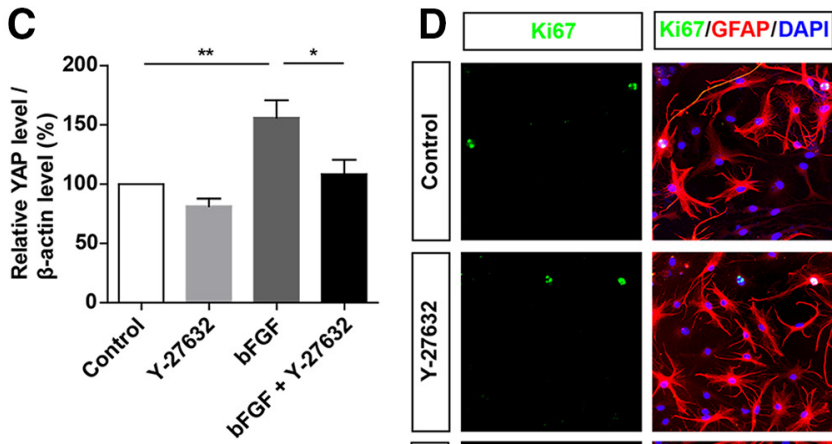

G

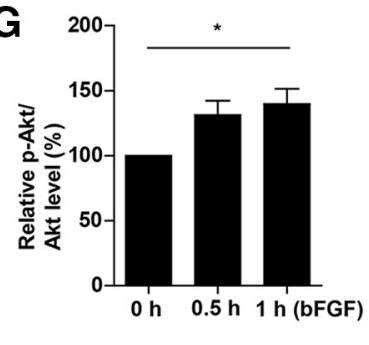

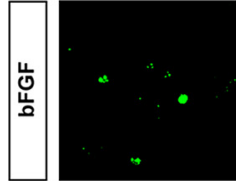
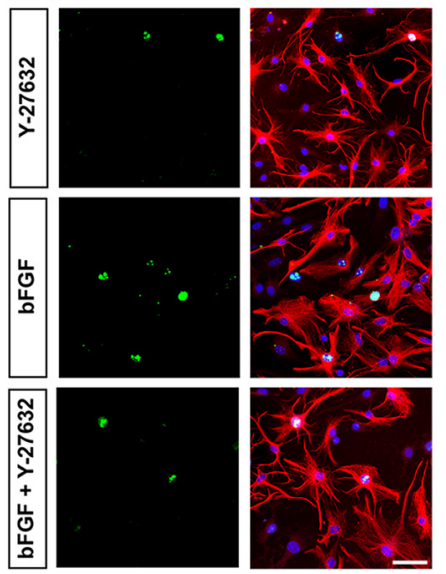

Figure 10. RhoA pathway was required for bFGF-induced activation of YAP and proliferation of astrocytes. $A$, Western blot analysis of p-YAP and YAP expression in WT astrocytes treated with bFGF $(100 \mathrm{ng} / \mathrm{ml})$ and/or Y27632 (10 $\mu \mathrm{M})$ for $1 \mathrm{~h}$. B, C, Quantitative analysis of the relative levels of p-YAP/YAP $(\boldsymbol{B})$ and YAP $(\boldsymbol{C})$ as shown in $\boldsymbol{A}(n=4$ per group). $\boldsymbol{D}$, Double immunostaining analysis of Ki67 (green) and GFAP (red) in WT astrocytes treated with bFGF $(100 \mathrm{ng} / \mathrm{ml})$ and/or Y27632 $(10 \mu \mathrm{m})$. E, Quantitative analysis of the percentages of Ki67 ${ }^{+} / \mathrm{GFAP}^{+}$proliferating astrocytes over total astrocytes as shown in $\boldsymbol{D}(n=6$ per group). $\boldsymbol{F}$, Western blot analysis of p-Akt and Akt expression in WT astrocytes treated with bFGF at indicated time points. $\boldsymbol{G}$, Quantitative analysis of the relative levels of p-Akt/Akt as shown in $\boldsymbol{F}(n=6$ per group). $\boldsymbol{B}, \boldsymbol{C}, \boldsymbol{E}$, Quantitative data were analyzed using one-way ANOVA with Bonferroni's multiple-comparison test. $\boldsymbol{G}$, Quantitative data were analyzed using one-way ANOVA with Dunnett's multiple-comparison test. ${ }^{*} p<0.05,{ }^{* *} p<0.01,{ }^{* * *} p<0.001$. Data are mean \pm SEM. Scale bars, $20 \mu \mathrm{m}$.

cant differences in CRM1 protein expression between $y a p^{+/+}$ and $y a p^{-/-}$astrocytes after bFGF treatment both in the Western blot (Fig. 12F, G) and qPCR analysis (Fig. 12H). These results suggested that YAP might regulate the expression of CRM1 and promote the cytoplasmic distribution of $\mathrm{p} 27^{\mathrm{Kip} 1}$ induced by bFGF.

We next examined whether CRM1 mediates the bFGFinduced cytoplasmic distribution of $\mathrm{p} 27^{\mathrm{Kip} 1}$ and promotes bFGF-induced proliferation. Astrocytes were treated with exonuclear transport inhibitors of CRM1, leptomycinB (LMB) as previously described (Connor et al., 2003; Ishida et al., 2015). We found that LMB significantly inhibited the increasing cytoplasmic location of $\mathrm{p} 27^{\mathrm{Kip} 1}$ in bFGF-induced astrocytes (Fig. 12I,J). Similarly, LMB blocked bFGF-induced proliferation of astrocytes (Fig. $12 \mathrm{~K}, L$ ). These results suggested that YAP promoted bFGFinduced astrocytic proliferation by negatively controlling nuclear distribution of $\mathrm{p} 27^{\mathrm{Kip} 1}$ mediated by CRM1.

\section{Activation of YAP signaling by MST1/2 inhibitor promoted} the formation of glial scars and functional recovery after SCI Recent studies have shown that XMU-MP-1 selectively inhibits MST1 and MST2 to enhance their downstream YAP activation and promotes regeneration in the liver and the intestine (Fan et al., 2016), and protected the function of heart (Triastuti et al., 2019) and brain (P. Zhang et al., 2019). Therefore, we examined whether XMU-MP-1 promotes the formation of glial scars and functional recovery of mice after SCI. We found that XMU-MP-1 treatment significantly promoted the motor recovery of mice in footprint assays at $14 \mathrm{~d}$ after SCI but did not significantly affect the mechanical sensory functions, compared with control mice (Fig. 13A-C). We further investigated the signaling cascades and found that XMU-MP-1 treatment activated YAP and promoted the expression of CRM1 and p $27^{\text {Kip } 1}$ (Fig. 13D-
I). Accordingly, the lesion size in the injured spinal cord was significantly decreased after XMU-MP-1 treatment, and the formation of glia scars was significantly increased after XMUMP-1 treatment (Fig. 13 J,K). These results suggested that the activation of YAP signaling by XMU-MP-1 increased the formation of glia scars and promoted the functional recovery of mice after SCI.

\section{Discussion}

In this study, we provide evidence of YAP's function in the formation of glial scars after SCI and propose its working mechanism (Fig. 14). In this model, bFGF is upregulated after SCI and promotes proliferation of astrocytes by activating YAP, which contributes to form glial scars and promotes neural regeneration. Conditional $\mathrm{KO}$ of yap in astrocytes inhibits the formation of glial scars and neural regeneration. Mechanistically, YAP promotes bFGF-induced proliferation of astrocytes by negatively controlling nuclear distribution of $\mathrm{p} 27^{\mathrm{Kip} 1}$ via CRM1. Moreover, bFGF regulates the activation of YAP through RhoA pathways. Collectively, these results show that the bFGF-RhoA-YAP-p $27^{\text {Kip } 1}$ axis positively regulates the formation of glial scars and promotes the neural regeneration after SCI.

Glial scars are dense barriers formed by proliferating reactive scar-forming astrocytes. They represent an effective repair and recovery strategy of CNS cells. The glial scars prevent the spreading of microbial infections and inflammatory responses. They also stimulate vascular remodeling to enhance nutritional and metabolic support to the nervous tissues (Stichel and Müller, 1998). Reactive astrocytes secrete several growth-inhibitory molecules that prevent axonal extensions (Yiu and He, 2006; Gervasi et al., 2008). However, recent reports have shown that scarforming astrocytes permit and efficiently promote the regeneration of appropriately stimulated CNS axons (Anderson et al., 
A

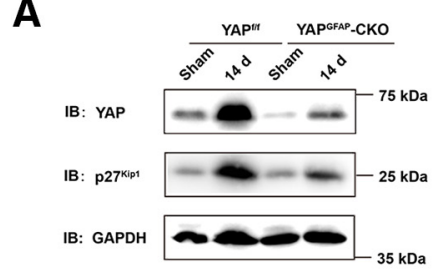

B

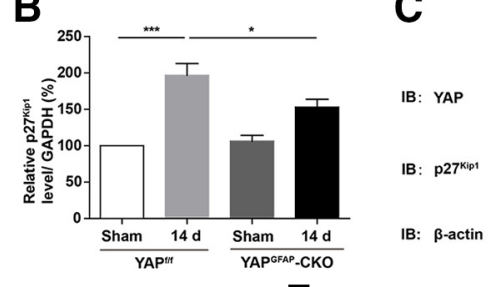

C

$\mathbf{F}$
$\mathbf{E}$

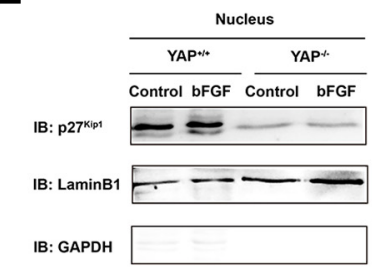

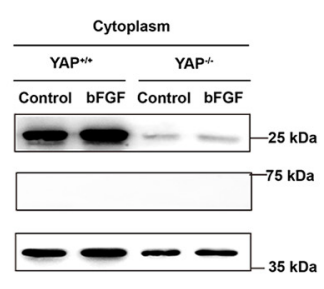

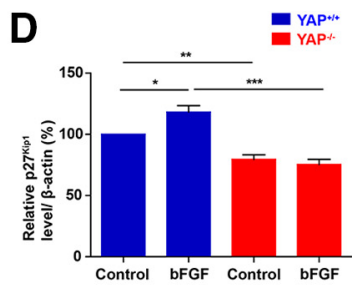

D

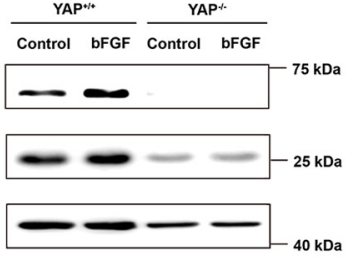

- YAP*
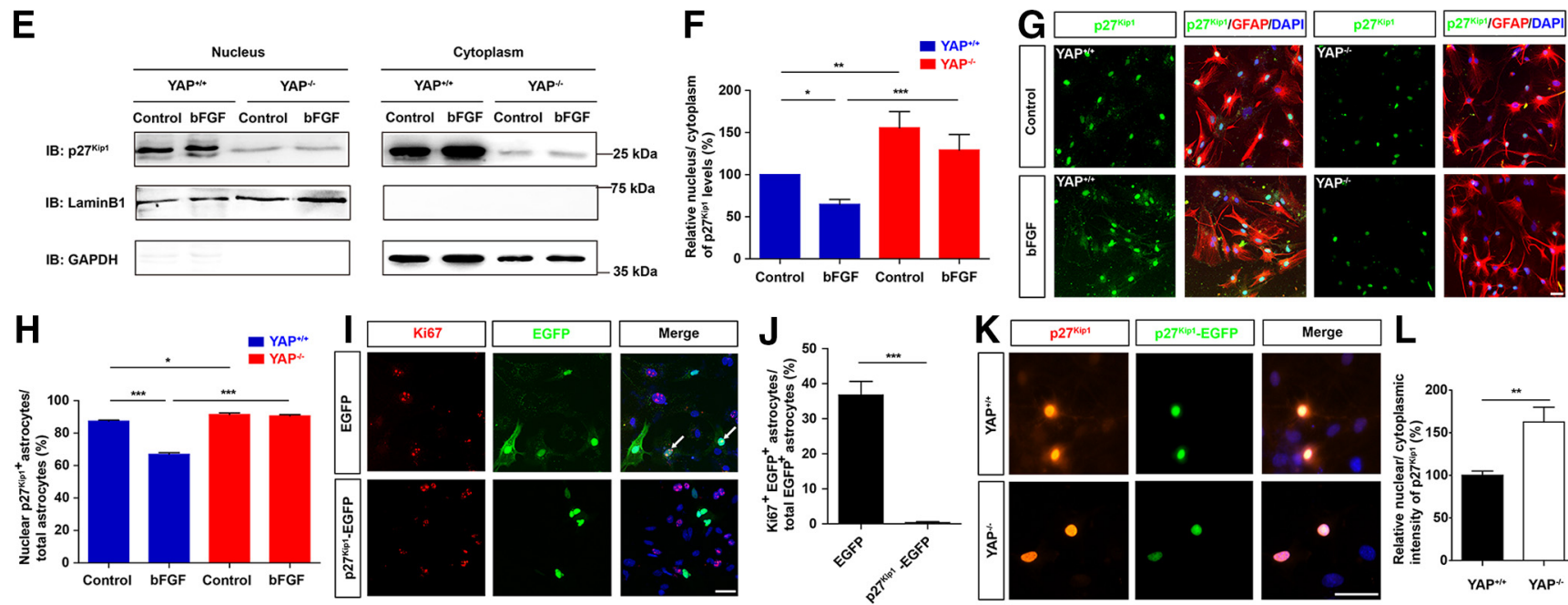

Figure 11. YAP promoted the proliferation of astrocytes through negatively controlling nuclear distribution of p $27^{\text {Kip1 }}$. A, Western blot analysis of YAP and p27 ${ }^{\text {Kip } 1}$ expression in spinal cords of 2-month-old male yafp and yap ${ }^{G F A P}$-CKO mice $14 \mathrm{~d}$ after SCI. B, Quantitative analysis of the relative levels of $\mathrm{p} 27^{\text {Kip } 1}$ as shown in $\boldsymbol{A}(n=4$ per group). $\boldsymbol{C}$, Western blot analysis of total YAP and p27 ${ }^{\text {Kip } 1}$ expression in yap ${ }^{+/+}$and yap ${ }^{-/-}$astrocytes treated with bFGF treatment $(100 \mathrm{ng} / \mathrm{ml})$ for $1 \mathrm{~h}$. $\boldsymbol{D}$, Quantitative analysis of the relative level of $\mathrm{p} 27^{\mathrm{Kip} 1}$ as shown in $\boldsymbol{C}(n=5$ per group). $\boldsymbol{E}$, Western blot analysis of the nuclear and cytoplasmic expression of $\mathrm{p} 27^{\mathrm{Kip} 1}$ in yap ${ }^{+/+}$and yap ${ }^{-/-}$astrocytes treated with bFGF treatment $(100 \mathrm{ng} / \mathrm{ml})$ for $1 \mathrm{~h}$. $\boldsymbol{F}$, Quantitative analysis of nucleus/cytoplasm ratio of $27^{\text {Kip } 1}$ protein levels as shown in $\boldsymbol{E}\left(n=8\right.$ per group). G, Double immunostaining analysis of GFAP (red) and p27 ${ }^{\text {Kip } 1}$ (green) in yap ${ }^{+/+}$astrocytes and yap ${ }^{-/-}$astrocytes treated with bFGF treatment $(100 \mathrm{ng} / \mathrm{ml})$ for $1 \mathrm{~h} . \boldsymbol{H}$, Quantitative analysis of the percentages of nuclear $\mathrm{p} 27^{\mathrm{Kip} 1+}$ astrocytes over total astrocytes as shown in $\mathbf{G}(n=6$ per group). II Immunostaining of Ki67 (red) in astrocytes transfected with EGFP or EGFP-p27 ${ }^{\text {kip } 1}$ plasmids for $48-72 \mathrm{~h}$ after bFGF treatment. $J$, Quantitative analysis of the percentages of Ki67 ${ }^{+} /$EGFP $^{+}$cells over EGFP ${ }^{+}$cells as shown in $\boldsymbol{I} . \boldsymbol{K}$, Immunostaining of $\mathrm{p} 27^{\mathrm{Kip} 1}$ (red) in yap $^{+/+}$and yap ${ }^{-/-}$astrocytes transfected with EGFP-p2 ${ }^{\text {kip } 1}$ plasmids for $48-72 \mathrm{~h}$. $\boldsymbol{L}$, Quantitative analysis of the nuclear and cytoplasmic intensity of p27 ${ }^{\text {Kip } 1 ~ i n ~ E G F P-p 27 ~}{ }^{\text {kip1 }}$ astrocytes between yap $^{+/+}$and yap ${ }^{-/-}$astrocytes as shown in $\boldsymbol{K}(n=7$ per group). White arrows indicate Ki67 and EGFP positive cells. $\boldsymbol{B}, \boldsymbol{D}, \boldsymbol{F}, \boldsymbol{H}, \mathbf{Q u a n t i t a t i v e}$ data were analyzed using one-way ANOVA with Bonferroni's multiple-comparison test.J, $L$, Quantitative data were analyzed using Student's unpaired two-tailed $t$ test. Data are mean \pm SEM. ${ }^{*} p<$ $0.05,{ }^{* *} p<0.01,{ }^{* * *} p<0.001$. Scale bars, $20 \mu \mathrm{m}$.

2016). Meanwhile, inhibition of the formation of glial scars may be detrimental in other pathological contexts of the CNS, including ischemia and experimental autoimmune encephalomyelitis (EAE) (Li et al., 2008; Voskuhl et al., 2009). This implies that astrocyte scar formation may facilitate axonal regeneration. Previous reports have shown that STAT-3 signaling and nuclear factor $\kappa \mathrm{B}$ are among key downstream mechanisms involved in the formation of glial scars after SCI (Herrmann et al., 2008; Chen et al., 2018b; Gaudet and Fonken, 2018). Impairing the formation of glial scars caused by deletion of astrocytic stat3 prevented axonal regeneration (Alluin et al., 2014; Anderson et al., 2016). Consistently, inhibiting the formation of glial scars by deleting astrocytic yap suppressed axonal regeneration and impaired the behavioral recovery in the medium and late stage after SCI, implying that compromised glial scar caused by yap deletion might inhibit nerve regeneration and recovery. Interestingly, YAP was upregulated and activated in astrocytes after SCI (Figs. $1 N$, $2 A, C)$. which is consistent with our previous studies that YAP was selectively expressed in cortical astrocytes and neural stem cells but was not detectable in cortical neurons (Huang et al., 2016a,b). Therefore, we postulate that astrocytic YAP may promote nerve regeneration by influencing the formation of glial scars. However, we also note that previous studies have shown that YAP is predominantly localized in neuronal somata in the spinal dorsal horn after chronic constriction injury of the sciatic nerve (CCI) (Xu et al., 2016). The discrepant results may be due to different animal model (CCI vs SCI) or different used antibodies.

We note that other key proteins of the Hippo pathway, such as MST1 and LATS1, are also involved in neural regeneration and recovery. As the upstream inhibitory protein, deletion of $m s t-1$ protects spinal motor neurons via enhancing autophagy flux. Moreover, inhibition of LATS1 promotes astrogliosis after SCI (M. Zhang et al., 2017; Y. Wang and Chen, 2018). Other reports show that YAP/TAZ participates in peripheral nerve injury progression, and inhibiting the activity of YAP/TAZ in spinal cord may suppress neuropathic pain (Li et al., 2013; Xu et al., 2016). This implicates YAP in the induction of neuropathic pain was in both early and later phases. Our results showed that YAP was upregulated and activated by SCI through suppression of Hippo kinases (Fig. 1) and deletion of astrocytic yap prevented neural regeneration and recovery. Moreover, XMU-MP-1 (an inhibitor of Hippo kinase MST1/2) injection activated YAP signaling and promoted the formation of glial scar and the functional recovery of mice after SCI. This discrepancy may be attributed to the different recovery processes of neurons in different injury models.

bFGF (FGF2), a growth factor with both mitogen and chemoattractant effect on astrocytes, is secreted by reactive astrocytes after injury to the CNS (Zhou et al., 2018). Previous reports have shown that bFGF regulates the differentiation of progenitor cells (Zittermann and Issekutz, 2006), withdrawal of myelin sheath (Zhou et al., 2018), and glial scar formation (Polikov et al., 
A The regulatory proteins of $p 27^{\text {Kip1 }}$

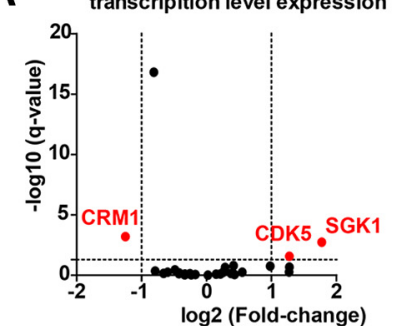

E

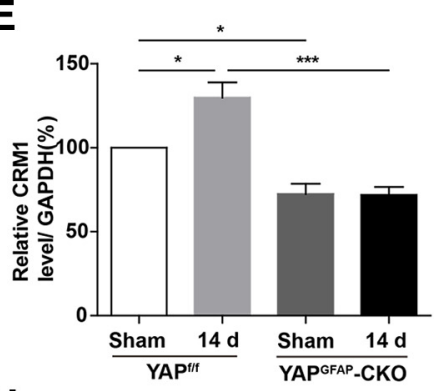

H

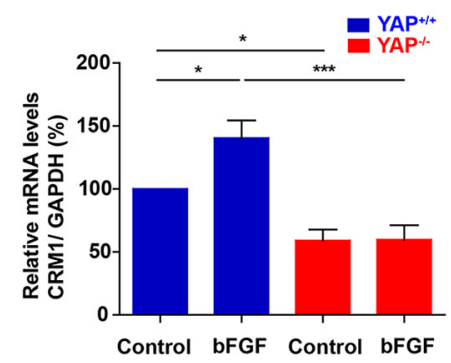

B

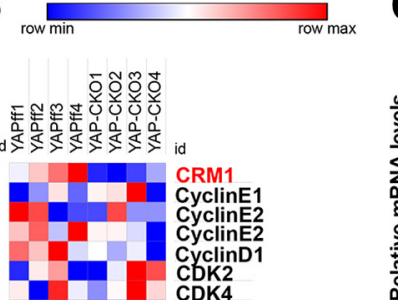

C

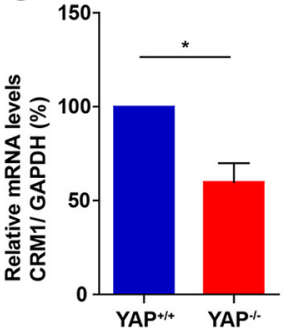

D

IB: CRM1

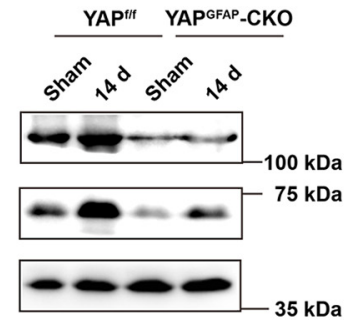

$F$

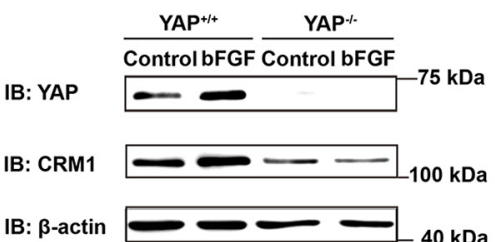

G

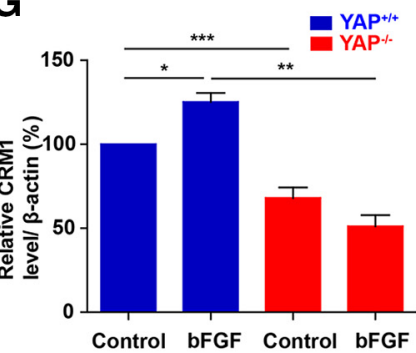

I

IB: p27 $7^{\text {ip1 }}$

IB: LaminB1
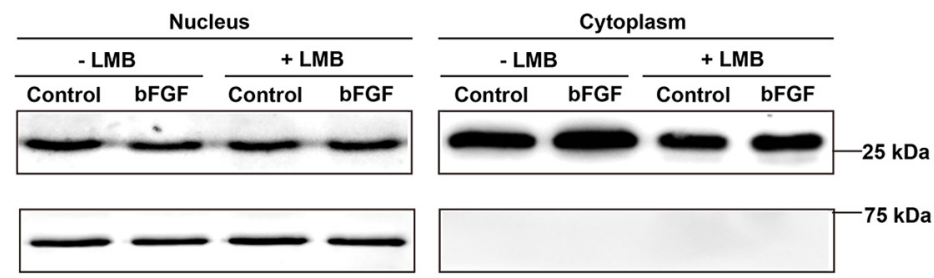

$75 \mathrm{kDa}$

IB: GAPDH

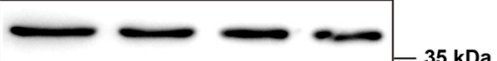

J

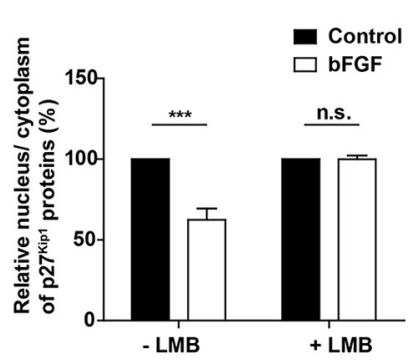

$\mathrm{K}$

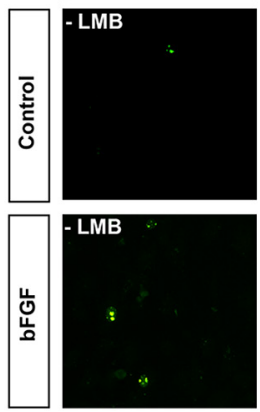

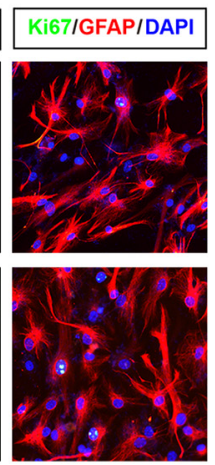
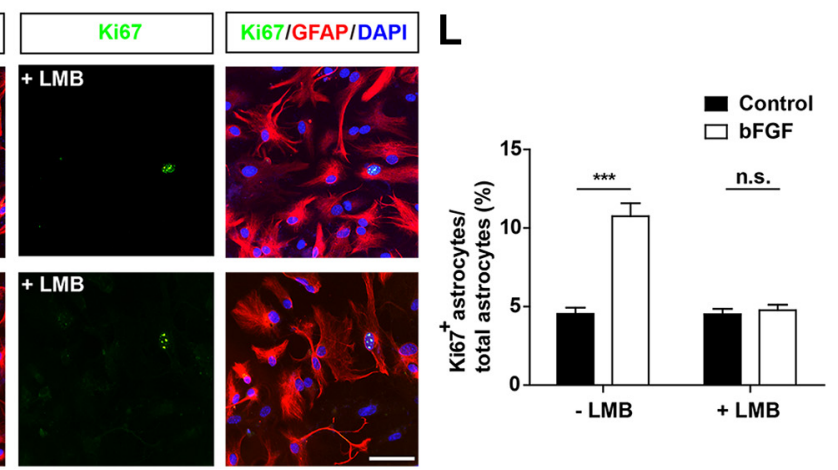

Figure 12. YAP promoted bFGF-induced proliferation of astrocytes through negatively controlling nuclear distribution of $\mathrm{p} 27^{\mathrm{Kip} 1}$ mediated by CRM1. $A$, The volcano plot of differential mRNAs of the regulatory genes of $27^{\text {Kip } 1}$ sequenced in yap ${ }^{+/+}$and yap ${ }^{-/-}$astrocytes. $\boldsymbol{B}$, Transcription level expression of the regulatory proteins of p $27^{\text {Kip } 1}$ in yap $^{+/+}$and yap ${ }^{-/-}$astrocytes. $\boldsymbol{C}$, Real-time PCR analysis showed the relative mRNA level of CRM1 in yap ${ }^{+/+}$and yap ${ }^{-/-}$astrocytes $(n=3$ per group). $\boldsymbol{D}$, Western blot analysis of YAP and CRM1 expression in spinal cords in 2-month-old male yap $^{f / f}$ and yap ${ }^{G F A P}$-CKO mice $14 \mathrm{~d}$ after SCI. $\boldsymbol{E}$, Quantitative analysis of the relative level of CRM1 ( $n=4$ per group) as shown in $\mathbf{D}$. F, Western blot analysis of YAP and CRM1 expression in yap ${ }^{+/+}$and yap $^{-/-}$astrocytes treated with bFGF treatment $(100 \mathrm{ng} / \mathrm{ml})$ for $1 \mathrm{~h}$. G, Quantitative analysis of the relative level of CRM1 ( $n=4$ per group) as shown in $\boldsymbol{F}$. $\boldsymbol{H}$, Real-time PCR analysis showed the relative mRNA level of CRM1 in yap ${ }^{+/+}$and yap ${ }^{-/-}$astrocytes treated with bFGF treatment $(100 \mathrm{ng} / \mathrm{ml})$ for $1 \mathrm{~h}(n=4$ per group). $I$, Western blot detected the nuclear and cytoplasmic expression of p $27^{\text {Kip } 1}$ in WT astrocytes treated with bFGF (100 ng/ml) for $1 \mathrm{~h}$ and/or were preincubated in LMB treatment at $5 \mathrm{ng} / \mathrm{ml}$ for $6 \mathrm{~h}$. J, Quantitative analysis of nucleus/cytoplasm ratio of $\mathrm{p} 27^{\text {Kip } 1}$ as shown in $\boldsymbol{I}(n=4$ per group). $\boldsymbol{K}$, Double immunostaining analysis of Ki67 (green) and GFAP (red) in WT astrocytes treated before and $1 \mathrm{~h}$ after bFGF ( $100 \mathrm{ng} / \mathrm{ml})$ and preincubated in LMB treatment at $5 \mathrm{ng} / \mathrm{ml}$ for $6 \mathrm{~h}$. $L$, Quantitative analysis of the percentages of Ki6 $6{ }^{+}{ }^{+} \mathrm{GFAP}{ }^{+}$proliferating astrocytes over total astrocytes as shown in $K(n=5$ per group). $C, J, L$, Quantitative data were analyzed using Student's unpaired two-tailed $t$ test. $E, G, H$, Quantitative data were analyzed using one-way ANOVA with Bonferroni's multiple-comparison test. Data are mean $\pm S E M .{ }^{*} p<0.05{ }^{* *} p<$ $0.01,{ }^{* * *} p<0.001$, n.s., not significant. Scale bars, $20 \mu \mathrm{m}$.

2009; Ye et al., 2015) after SCI. It also participates in the formation of glial scars by increasing astrocytic proliferation (Zhou et al., 2018). Consistent with these studies, our study showed that bFGF was upregulated, and this promoted the formation of glial scars due to activation of YAP after SCI. Interestingly, bFGF injection in vivo indeed activated YAP and promoted the formation of glial scars and the functional recovery of mice after SCI (Fig. 7).
Previous studies indeed have shown that bFGF binds to its FGF receptors and activates downstream signaling pathways, including the PI3K-Akt pathways, leading to the suppression of the Hippo pathway and activation of YAP in the FTSECs, and the activation of YAP promotes the bFGF-induced proliferation of FTSECs (Hua et al., 2016). Similarly, we also found that bFGF activated the PI3K-Akt pathway kinase proteins and the RhoA 
A

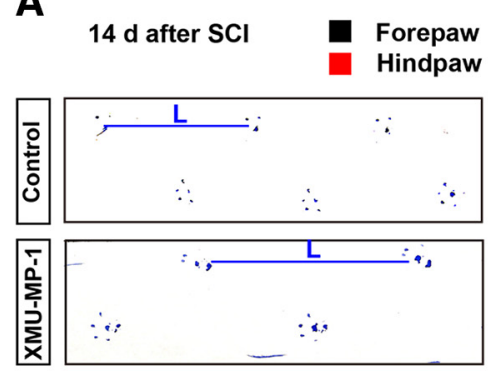

B

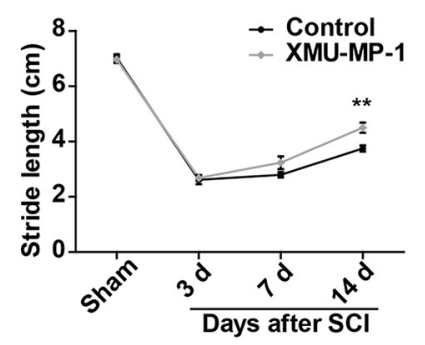

C

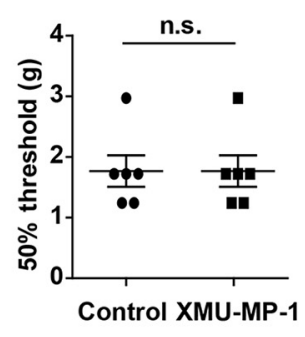

D

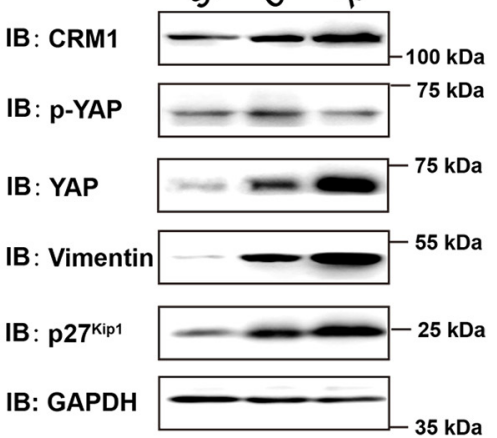

H

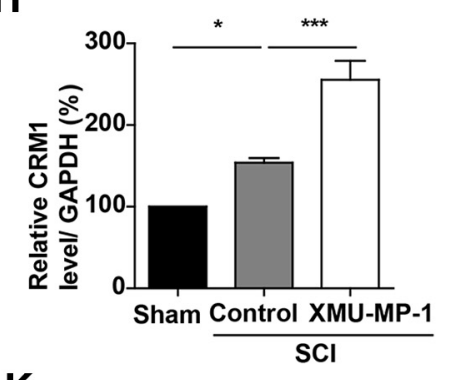

K

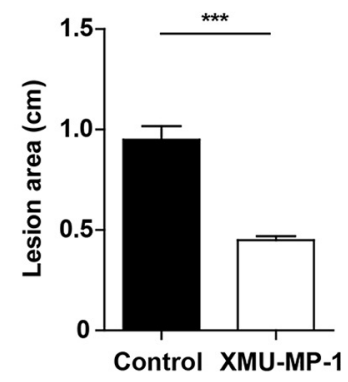

Figure 13. Activation of YAP signaling by MST1/2 inhibitor promoted formation of glial scars and functional recovery of mice after SCI. $A$, Representative footprint images of control and XMU-MP-1-treated mice at $14 \mathrm{~d}$ after SCI. B, Quantitative analysis of stride length of sham mice, control, and XMU-MP-1-treated mice at indicated days after SCI ( $n=6$ per group). C, Quantitative analysis of $50 \%$ threshold of von Frey hair test to the plantar surface hindpaw in control and XMU-MP-1-treated mice after SCI ( $n=6$ per group). D, Western blot analysis of CRM1, p-YAP, YAP, vimentin, and p27 ${ }^{\text {Kip1 }}$ expression in spinal cords of control and XMU-MP-1-treated mice at $14 \mathrm{~d}$ after SCI. $\boldsymbol{E}-$ I, Quantitative analysis of p-YAP/YAP (E), YAP (F), vimentin (G), CRM1 (H), and p27 Kip1 (I) protein levels as shown in $\boldsymbol{D}(n=3$ per group). $J$, Immunostaining of GFAP (red) in spinal cords of control and XMU-MP-1-treated mice at $14 \mathrm{~d}$ after $\mathrm{SCl}$. $\boldsymbol{K}$, Quantitative analysis of lesioned size in spinal cords as shown in $J$. White dashed lines indicate the injury sites. J, Images of selected regions (white squares) are shown at higher magnification. $B, Q$ uantitative data were analyzed using two-way ANOVA with Bonferroni post tests. E-I, Quantitative data were analyzed using one-way ANOVA with Bonferroni's multiple-comparison test. $C, \boldsymbol{K}$, Data were analyzed using Student's unpaired two-tailed $t$ test. ${ }^{*} p<0.05,{ }^{* *} p<0.01,{ }^{* * *} p<0.001$, n.s., not significant. Data are mean \pm SEM. Scale bars, $20 \mu \mathrm{m}$.

pathway was required for the bFGF-induced activation of YAP. It is interesting to test whether the cross talk between RhoA pathway and PI3K-Akt pathway regulates the activity of YAP in astrocytes in future.

Previous studies have shown that YAP promotes the proliferation of several types of cells by downregulating the expression of p27 ${ }^{\text {Kipl }}$ (Nakayama et al., 2004; Jang et al., 2017). However, in this study, yap deletion abolished the increase of $\mathrm{p} 27^{\mathrm{Kip} 1}$ protein expression in astrocytes induced by bFGF and after SCI. These results suggested that YAP upregulated the expression of total $\mathrm{p} 27^{\mathrm{kip} 1}$ in astrocytes after SCI or with bFGF treatment. Nevertheless, evidence from some studies indicates that YAP regulates cell proliferation, such as neuroblastoma cells, by modulating the nuclear and cytoplasmic trafficking of p27 ${ }^{\mathrm{Kip} 1}$ (Li et al., 2009; Kim and Kang, 2018; Shen et al., 2019). Consistent with these studies, we found that deletion of yap in astrocytes increased the nucleus/cytoplasm ratio of $\mathrm{p} 27^{\mathrm{Kip} 1}$, thereby reducing astrocytic proliferation. CRM1, as a nuclear export protein, mediates the translocation of $\mathrm{p} 27^{\mathrm{Kip} 1}$ from the nucleus to the cytoplasm and promotes cell proliferation as a consequence (Bencivenga et al., 2014; Ishida et al., 2015). Indeed, our results confirmed the decreased expression of CRM1 in yap ${ }^{-/-}$astrocytes and yap ${ }^{G F A P}$ CKO mice after SCI, and CRM1-dependent nuclear export of p27 ${ }^{\text {Kip } 1}$ after bFGF treatment. This indicates that CRM1 may mediate the effects of YAP on bFGF-induced astrocytic proliferation through the nuclear export of $\mathrm{p} 27^{\mathrm{Kip} 1}$. Our preliminary results of CHIP assay showed that yap did not bind with the promoter of CRM1 in cultured astrocytes (data not shown), which suggest that YAP may regulate the expression of CRM1 indirectly. However, a recent study has shown that CRM1 can also mediate the nuclear export of YAP (Fang et al., 2018). Therefore, CRM1 may partially participate in the nuclear export of 


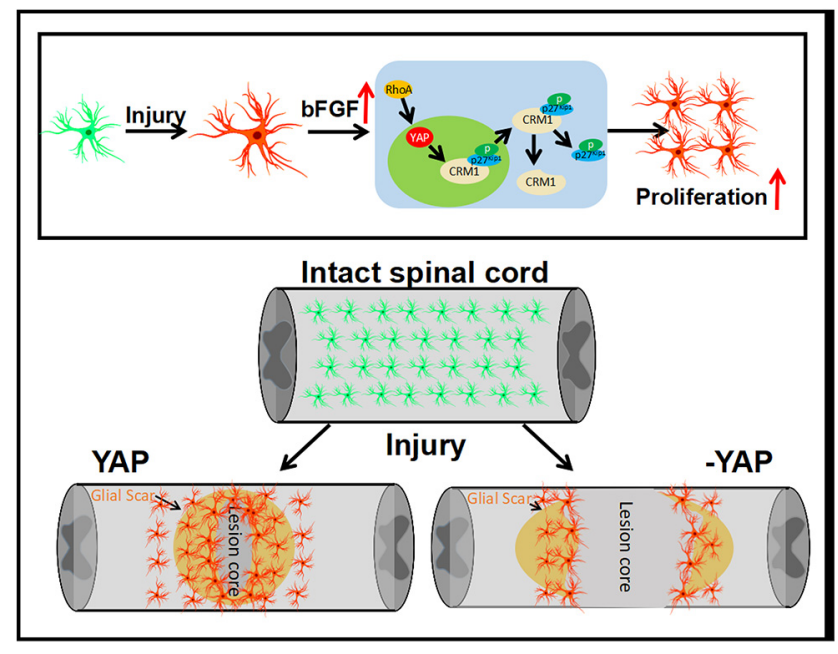

Figure 14. A working model illustrates YAP's function in glial scar formation after $\mathrm{SCl}$ and bFGF-RhoA-YAP-p27 ${ }^{\text {Kip } 1}$ pathway axis for positively regulating glial scars. In this model, bFGF is upregulated after $\mathrm{SCl}$ and promotes the proliferation of astrocytes via activating YAP, which contributes to the formation of glial scars and promotion of neural regeneration after $\mathrm{SCl}$. Conditional KO yap in astrocytes impairs the formation of glial scars and neural regeneration. Mechanistically, YAP promotes bFGF-induced proliferation of astrocytes through negatively controlling nuclear distribution of $\mathrm{p} 27^{\text {Kip } 1}$ mediated by CRM1.

YAP, perhaps competing for the nuclear export of p2 $7^{\mathrm{Kip} 1}$. Nevertheless, the role of CRM1-mediated nuclear export of YAP needs to be clarified. Moreover, whether CRM1-mediated nuclear export of YAP contributes to bFGF-induced astrocytic proliferation requires further validation.

In conclusion, our study not only discovers that YAP promotes the formation of glial scars after SCI, but also implicates bFGF-RhoA-YAP-p2 $7^{\text {Kip } 1}$ axis in the positive regulation of astrocytic proliferation. These findings suggest that YAP participates in the formation of glial scars, induced by bFGF after SCI through the regulation of astrocytic proliferation via negatively controlling nuclear distribution of p2 $7^{\text {Kip1 }}$ mediated by CRM1, which may be an option of design of therapeutic intervention strategies to accelerate the functional recovery after SCI.

\section{References}

Alluin O, Delivet-Mongrain H, Gauthier MK, Fehlings MG, Rossignol S, Karimi-Abdolrezaee S (2014) Examination of the combined effects of chondroitinase $\mathrm{ABC}$, growth factors and locomotor training following compressive spinal cord injury on neuroanatomical plasticity and kinematics. PLoS One 9:e111072.

Anderson MA, Burda JE, Ren Y, Ao Y, O’Shea TM, Kawaguchi R, Coppola G, Khakh BS, Deming TJ, Sofroniew MV (2016) Astrocyte scar formation aids central nervous system axon regeneration. Nature 532:195-200.

Bencivenga D, Tramontano A, Borgia A, Negri A, Caldarelli I, Oliva A, Perrotta S, Della Ragione F, Borriello A (2014) P27Kip1 serine 10 phosphorylation determines its metabolism and interaction with cyclindependent kinases. Cell Cycle 13:3768-3782.

Brennan FH, Gordon R, Lao HW, Biggins PJ, Taylor SM, Franklin RJ, Woodruff TM, Ruitenberg MJ (2015) The complement receptor C5aR controls acute inflammation and astrogliosis following spinal cord injury. J Neurosci 35:6517-6531.

Brown A, Wang L, Jung P (2005) Stochastic simulation of neurofilament transport in axons: the "stop-and-go" hypothesis. Mol Biol Cell 16: $4243-4255$.

Cai J, Zhang N, Zheng Y, de Wilde RF, Maitra A, Pan D (2010) The hippo signaling pathway restricts the oncogenic potential of an intestinal regeneration program. Genes Dev 24:2383-2388.

Chen G, Luo X, Qadri MY, Berta T, Ji RR (2018a) Sex-dependent glial signaling in pathological pain: distinct roles of spinal microglia and astrocytes. Neurosci Bull 34:98-108.
Chen M, Geoffroy CG, Meves JM, Narang A, Li Y, Nguyen MT, Khai VS, Kong X, Steinke CL, Carolino KI, Elzière L, Goldberg MP, Jin Y, Zheng B (2018b) Leucine zipper-bearing kinase is a critical regulator of astrocyte reactivity in the adult mammalian CNS. Cell Rep 22:3587-3597.

Chen Z, Li Z, Jiang C, Jiang X, Zhang J (2019) MiR-92b-3p promotes neurite growth and functional recovery via the PTEN/AKT pathway in acute spinal cord injury. J Cell Physiol 234:23043-23052.

Connor MK, Kotchetkov R, Cariou S, Resch A, Lupetti R, Beniston RG, Melchior F, Hengst L, Slingerland JM (2003) CRM1/Ran-mediated nuclear export of p27(Kip1) involves a nuclear export signal and links p27 export and proteolysis. Mol Biol Cell 14:201-213.

Corum DG, Tsichlis PN, Muise-Helmericks RC (2014) AKT3 controls mitochondrial biogenesis and autophagy via regulation of the major nuclear export protein CRM-1. FASEB J 28:395-407.

de Almeida FM, Marques SA, Ramalho Bdos S, Rodrigues RF, Cadilhe DV, Furtado D, Kerkis I, Pereira LV, Rehen SK, Martinez AM (2011) Human dental pulp cells: a new source of cell therapy in a mouse model of compressive spinal cord injury. J Neurotrauma 28:1939-1949.

Fan F, He Z, Kong LL, Chen Q, Yuan Q, Zhang S, Ye J, Liu H, Sun X, Geng J, Yuan L, Hong L, Xiao C, Zhang W, Sun X, Li Y, Wang P, Huang L, Wu X, Ji Z, et al. (2016) Pharmacological targeting of kinases MST1 and MST2 augments tissue repair and regeneration. Sci Transl Med 8:352ra108.

Fang L, Teng H, Wang Y, Liao G, Weng L, Li Y, Wang X, Jin J, Jiao C, Chen L, Peng X, Chen J, Yang Y, Fang H, Han D, Li C, Jin X, Zhang S, Liu Z, Liu M, et al. (2018) SET1A-mediated mono-methylation at K342 regulates YAP activation by blocking its nuclear export and promotes tumorigenesis. Cancer Cell 34:103-118.e9.

Fang L, Barber AJ, Shenberger JS (2014) Regulation of fibroblast growth factor 2 expression in oxygen-induced retinopathy. Invest Ophthalmol Vis Sci 56:207-215.

Faulkner JR, Herrmann JE, Woo MJ, Tansey KE, Doan NB, Sofroniew MV (2004) Reactive astrocytes protect tissue and preserve function after spinal cord injury. J Neurosci 24:2143-2155.

Faw TD, Lerch JK, Thaxton TT, Deibert RJ, Fisher LC, Basso DM (2018) Unique sensory and motor behavior in Thyl-GFP-M mice before and after spinal cord injury. J Neurotrauma 35:2167-2182.

Fehlings MG, Tator CH (1995) The relationships among the severity of spinal cord injury, residual neurological function, axon counts, and counts of retrogradely labeled neurons after experimental spinal cord injury. Exp Neurol 132:220-228.

Fitch MT, Silver J (2008) CNS injury, glial scars, and inflammation: inhibitory extracellular matrices and regeneration failure. Exp Neurol 209:294301.

Follesa P, Wrathall JR, Mocchetti I (1994) Increased basic fibroblast growth factor mRNA following contusive spinal cord injury. Brain Res Mol Brain Res 22:1-8.

Frik J, Merl-Pham J, Plesnila N, Mattugini N, Kjell J, Kraska J, Gomez RM, Hauck SM, Sirko S, Götz M (2018) Cross-talk between monocyte invasion and astrocyte proliferation regulates scarring in brain injury. EMBO Rep 19:e45294.

Gaudet AD, Fonken LK (2018) Glial cells shape pathology and repair after spinal cord injury. Neurotherapeutics 15:554-577.

Ge Z, Li B, Zhou X, Yang Y, Zhang J (2016) Basic fibroblast growth factor activates beta-catenin/RhoA signaling in pulmonary fibroblasts with chronic obstructive pulmonary disease in rats. Mol Cell Biochem 423: 165-174.

Gervasi NM, Kwok JC, Fawcett JW (2008) Role of extracellular factors in axon regeneration in the CNS: implications for therapy. Regen Med 3:907-923.

He Y, Xu H, Xiang Z, Yu H, Xu L, Guo Y, Tian Y, Shu R, Yang X, Xue C, Zhao M, He Y, Han X, Bai D (2019) YAP regulates periodontal ligament cell differentiation into myofibroblast interacted with RhoA/ROCK pathway. J Cell Physiol 234:5086-5096.

Herrmann JE, Imura T, Song B, Qi J, Ao Y, Nguyen TK, Korsak RA, Takeda K, Akira S, Sofroniew MV (2008) STAT3 is a critical regulator of astrogliosis and scar formation after spinal cord injury. J Neurosci 28:7231-7243.

Hnit SS, Xie C, Yao M, Holst J, Bensoussan A, De Souza P, Li Z, Dong Q (2015) p27(Kip1) signaling: transcriptional and post-translational regulation. Int J Biochem Cell Biol 68:9-14.

Hoffman PN, Lasek RJ (1975) The slow component of axonal transport: identification of major structural polypeptides of the axon and their generality among mammalian neurons. J Cell Biol 66:351-366. 
Hua G, Lv X, He C, Remmenga SW, Rodabough KJ, Dong J, Yang L, Lele SM, Yang P, Zhou J, Karst A, Drapkin RI, Davis JS, Wang C (2016) YAP induces high-grade serous carcinoma in fallopian tube secretory epithelial cells. Oncogene 35:2247-2265.

Huang Z, Wang Y, Hu G, Zhou J, Mei L, Xiong WC (2016a) YAP is a critical inducer of SOCS3, preventing reactive astrogliosis. Cereb Cortex 26:2299-2310.

Huang Z, Hu J, Pan J, Wang Y, Hu G, Zhou J, Mei L, Xiong WC (2016b) YAP stabilizes SMAD1 and promotes BMP2-induced neocortical astrocytic differentiation. Development 143:2398-2409.

Huang Z, Sun D, Hu JX, Tang FL, Lee DH, Wang Y, Hu G, Zhu XJ, Zhou J, Mei L, Xiong WC (2016c) Neogenin promotes BMP2 activation of YAP and Smad 1 and enhances astrocytic differentiation in developing mouse neocortex. J Neurosci 36:5833-5849.

Ishida N, Hara T, Kamura T, Yoshida M, Nakayama K, Nakayama KI (2015) Phosphorylation of p27Kip1 on serine 10 is required for its binding to CRM1 and nuclear export. J Biol Chem 290:6754.

Jang W, Kim T, Koo JS, Kim SK, Lim DS (2017) Mechanical cue-induced YAP instructs Skp2-dependent cell cycle exit and oncogenic signaling. EMBO J 36:2510-2528.

Johnson R, Halder G (2014) The two faces of hippo: targeting the hippo pathway for regenerative medicine and cancer treatment. Nat Rev Drug Discov 13:63-79.

Joshi M, Fehlings MG (2002a) Development and characterization of a novel, graded model of clip-compressive spinal cord injury in the mouse: 1. Clip design, behavioral outcomes, and histopathology. J Neurotrauma 19:175-190.

Joshi M, Fehlings MG (2002b) Development and characterization of a novel, graded model of clip-compressive spinal cord injury in the mouse: 2. Quantitative neuroanatomical assessment and analysis of the relationships between axonal tracts, residual tissue, and locomotor recovery. J Neurotrauma 19:191-203.

Kaneko S, Iwanami A, Nakamura M, Kishino A, Kikuchi K, Shibata S, Okano HJ, Ikegami T, Moriya A, Konishi O, Nakayama C, Kumagai K, Kimura T, Sato Y, Goshima Y, Taniguchi M, Ito M, He Z, Toyama Y, Okano H (2006) A selective Sema3A inhibitor enhances regenerative responses and functional recovery of the injured spinal cord. Nat Med 12:13801389.

Khakh BS, Sofroniew MV (2015) Diversity of astrocyte functions and phenotypes in neural circuits. Nat Neurosci 18:942-952.

Kim JE, Kang TC (2018) Nucleocytoplasmic p27(Kip1) export is required for ERK1/2-mediated reactive astroglial proliferation following status epilepticus. Front Cell Neurosci 12:152.

Koshinaga M, Sanon HR, Whittemore SR (1993) Altered acidic and basic fibroblast growth factor expression following spinal cord injury. Exp Neurol 120:32-48.

Lau AN, Curtis SJ, Fillmore CM, Rowbotham SP, Mohseni M, Wagner DE, Beede AM, Montoro DT, Sinkevicius KW, Walton ZE, Barrios J, Weiss DJ, Camargo FD, Wong KK, Kim CF (2014) Tumor-propagating cells and Yap/Taz activity contribute to lung tumor progression and metastasis. EMBO J 33:468 - 481.

Li D, Ji JX, Xu YT, Ni HB, Rui Q, Liu HX, Jiang F, Gao R, Chen G (2018) Inhibition of Lats1/p-YAP1 pathway mitigates neuronal apoptosis and neurological deficits in a rat model of traumatic brain injury. CNS Neurosci Ther 24:906-916.

Li L, Lundkvist A, Andersson D, Wilhelmsson U, Nagai N, Pardo AC, Nodin C, Ståhlberg A, Aprico K, Larsson K, Yabe T, Moons L, Fotheringham A, Davies I, Carmeliet P, Schwartz JP, Pekna M, Kubista M, Blomstrand F, Maragakis N, et al. (2008) Protective role of reactive astrocytes in brain ischemia. J Cereb Blood Flow Metab 28:468-481.

Li N, Lim G, Chen L, McCabe MF, Kim H, Zhang S, Mao J (2013) Spinal expression of hippo signaling components YAP and TAZ following peripheral nerve injury in rats. Brain Res 1535:137-147.

Li X, Tang X, Jablonska B, Aguirre A, Gallo V, Luskin MB (2009) p27(KIP1) regulates neurogenesis in the rostral migratory stream and olfactory bulb of the postnatal mouse. J Neurosci 29:2902-2914.

Li Z, Chen T, Cao Y, Jiang X, Lin H, Zhang J, Chen Z (2019) Pros and cons: autophagy in acute spinal cord injury. Neurosci Bull 35:941-945.

Ma M, Basso DM, Walters P, Stokes BT, Jakeman LB (2001) Behavioral and histological outcomes following graded spinal cord contusion injury in the C57BL/6 mouse. Exp Neurol 169:239-254.

Mao L, Wang H, Qiao L, Wang X (2010) Disruption of Nrf2 enhances the upregulation of nuclear factor-kappaB activity, tumor necrosis factoralpha, and matrix metalloproteinase- 9 after spinal cord injury in mice. Mediators Inflamm 2010:238321.

Marques SA, Garcez VF, Del Bel EA, Martinez AM (2009) A simple, inexpensive and easily reproducible model of spinal cord injury in mice: morphological and functional assessment. J Neurosci Methods 177:183-193.

Marques SA, Almeida FM, Fernandes AM, dos Santos Souza C, Cadilhe DV, Rehen SK, Martinez AM (2010) Predifferentiated embryonic stem cells promote functional recovery after spinal cord compressive injury. Brain Res 1349:115-128.

Maugeri-Saccà M, De Maria R (2018) The hippo pathway in normal development and cancer. Pharmacol Ther 186:60-72.

Mocchetti I, Rabin SJ, Colangelo AM, Whittemore SR, Wrathall JR (1996) Increased basic fibroblast growth factor expression following contusive spinal cord injury. Exp Neurol 141:154-164.

Nakayama K, Nagahama H, Minamishima YA, Miyake S, Ishida N, Hatakeyama S, Kitagawa M, Iemura S, Natsume T, Nakayama KI (2004) Skp2-mediated degradation of p27 regulates progression into mitosis. Dev Cell 6:661-672.

Okada S, Hara M, Kobayakawa K, Matsumoto Y, Nakashima Y (2018) Astrocyte reactivity and astrogliosis after spinal cord injury. Neurosci Res 126:39-43

Pan D (2010) The hippo signaling pathway in development and cancer. Dev Cell 19:491-505.

Pekny M, Pekna M, Messing A, Steinhäuser C, Lee JM, Parpura V, Hol EM, Sofroniew MV, Verkhratsky A (2016) Astrocytes: a central element in neurological diseases. Acta Neuropathol 131:323-345.

Piccolo S, Dupont S, Cordenonsi M (2014) The biology of YAP/TAZ: hippo signaling and beyond. Physiol Rev 94:1287-1312.

Polikov VS, Su EC, Ball MA, Hong JS, Reichert WM (2009) Control protocol for robust in vitro glial scar formation around microwires: essential roles of bFGF and serum in gliosis. J Neurosci Methods 181:170-177.

Qu J, Zhao H, Li Q, Pan P, Ma K, Liu X, Feng H, Chen Y (2018) MST1 suppression reduces early brain injury by inhibiting the NF- $\kappa \mathrm{B} / \mathrm{MMP}-9$ pathway after subarachnoid hemorrhage in mice. Behav Neurol 2018: 6470957.

Ren ZW, Zhou JG, Xiong ZK, Zhu FZ, Guo XD (2019) Effect of exosomes derived from MiR-133b-modified ADSCs on the recovery of neurological function after SCI. Eur Rev Med Pharmacol Sci 23:52-60.

Shen A, Liu Y, Zhao J, Qin J, Shi S, Chen M, Gao S, Xiao F, Lu Q, Cheng C (2008) Temporal-spatial expressions of p27kipl and its phosphorylation on serine-10 after acute spinal cord injury in adult rat: implications for post-traumatic glial proliferation. Neurochem Int 52:1266-1275.

Shen X, Xu X, Xie C, Liu H, Yang D, Zhang J, Wu Q, Feng W, Wang L, Du L, Xuan L, Meng C, Zhang H, Wang W, Wang Y, Xie T, Huang Z (2019) YAP promotes the proliferation of neuroblastoma cells through decreasing the nuclear location of p27(Kip1) mediated by Akt. Cell Prolif 2019: e12734.

Silver J, Miller JH (2004) Regeneration beyond the glial scar. Nat Rev Neurosci 5:146-156.

Sofroniew MV (2009) Molecular dissection of reactive astrogliosis and glial scar formation. Trends Neurosci 32:638-647.

Sofroniew MV (2014) Astrogliosis. Cold Spring Harb Perspect Biol 7:a020420.

Sofroniew MV, Vinters HV (2010) Astrocytes: biology and pathology. Acta Neuropathol 119:7-35.

Stichel CC, Müller HW (1998) The CNS lesion scar: new vistas on an old regeneration barrier. Cell Tissue Res 294:1-9.

Tao Y, Black IB, DiCicco-Bloom E (1996) Neurogenesis in neonatal rat brain is regulated by peripheral injection of basic fibroblast growth factor (bFGF). J Comp Neurol 376:653-663.

Tran AP, Warren PM, Silver J (2018) The biology of regeneration failure and success after spinal cord injury. Physiol Rev 98:881-917.

Triastuti E, Nugroho AB, Zi M, Prehar S, Kohar YS, Bui TA, Stafford N, Cartwright EJ, Abraham S, Oceandy D (2019) Pharmacological inhibition of hippo pathway, with the novel kinase inhibitor XMU-MP-1, protects the heart against adverse effects during pressure overload. Br J Pharmacol 176:3956-3971.

Voskuhl RR, Peterson RS, Song B, Ao Y, Morales LB, Tiwari-Woodruff S, Sofroniew MV (2009) Reactive astrocytes form scar-like perivascular barriers to leukocytes during adaptive immune inflammation of the CNS. J Neurosci 29:11511-11522. 
Wagner JP, Black IB, DiCicco-Bloom E (1999) Stimulation of neonatal and adult brain neurogenesis by subcutaneous injection of basic fibroblast growth factor. J Neurosci 19:6006-6016.

Wang P, Xie ZD, Xie CN, Lin CW, Wang JL, Xuan LN, Zhang CW, Wang Y, Huang ZH, Teng HL (2018) AMP-activated protein kinase-dependent induction of autophagy by erythropoietin protects against spinal cord injury in rats. CNS Neurosci Ther 24:1185-1195.

Wang Y, Chen M (2018) Decreased expression of LATS1 correlates with astrogliosis after spinal cord injury. Biochem Biophys Res Commun 505:151-156.

Wang Y, Hu G, Liu F, Wang X, Wu M, Schwarz JJ, Zhou J (2014) Deletion of yes-associated protein (YAP) specifically in cardiac and vascular smooth muscle cells reveals a crucial role for YAP in mouse cardiovascular development. Circ Res 114:957-965.

Wang YF, Zu JN, Li J, Chen C, Xi CY, Yan JL (2014) Curcumin promotes the spinal cord repair via inhibition of glial scar formation and inflammation. Neurosci Lett 560:51-56.

Wang ZG, Cheng Y, Yu XC, Ye LB, Xia QH, Johnson NR, Wei X, Chen DQ, Cao G, Fu XB, Li XK, Zhang HY, Xiao J (2016) bFGF protects against blood-brain barrier damage through junction protein regulation via PI3K-akt-Racl pathway following traumatic brain injury. Mol Neurobiol 53:7298-7311.

Wanner IB, Anderson MA, Song B, Levine J, Fernandez A, Gray-Thompson Z, Ao Y, Sofroniew MV (2013) Glial scar borders are formed by newly proliferated, elongated astrocytes that interact to corral inflammatory and fibrotic cells via STAT3-dependent mechanisms after spinal cord injury. J Neurosci 33:12870-12886.

Xu N, Wu MZ, Deng XT, Ma PC, Li ZH, Liang L, Xia MF, Cui D, He DD, Zong Y, Xie Z, Song XJ (2016) Inhibition of YAP/TAZ activity in spinal cord suppresses neuropathic pain. J Neurosci 36:10128-10140.

Xu Y, Jiang Y, Wang L, Huang J, Wen J, Lv H, Wu X, Wan C, Yu C, Zhang W, Zhao J, Zhou Y, Chen Y (2019) Thymosin alpha-1 inhibits complete Freund's adjuvant-induced pain and production of microglia-mediated pro-inflammatory cytokines in spinal cord. Neurosci Bull 35:637-648.

Ye J, Lin H, Mu J, Cui X, Ying H, Lin M, Wu L, Weng J, Lin X (2010) Effect of basic fibroblast growth factor on hippocampal cholinergic neurons in a rodent model of ischaemic encephalopathy. Basic Clin Pharmacol Toxicol 107:931-939.

Ye LB, Yu XC, Xia QH, Yang Y, Chen DQ, Wu F, Wei XJ, Zhang X, Zheng BB, Fu XB, Xu HZ, Li XK, Xiao J, Zhang HY (2016) Regulation of caveolin-1 and junction proteins by bFGF contributes to the integrity of blood-spinal cord barrier and functional recovery. Neurotherapeutics 13:844-858.
Ye L, Yang Y, Zhang X, Cai P, Li R, Chen D, Wei X, Zhang X, Xu H, Xiao J, Li $X$, Lin L, Zhang H (2015) The role of bFGF in the excessive activation of astrocytes is related to the inhibition of TLR4/NF $\kappa$ B signals. Int J Mol Sci 17:E37.

Yiu G, He Z (2006) Glial inhibition of CNS axon regeneration. Nat Rev Neurosci 7:617-627.

Yu FX, Zhao B, Guan KL (2015) Hippo pathway in organ size control, tissue homeostasis, and cancer. Cell 163:811-828.

Yuan A, Rao MV, Veeranna, Nixon RA (2017) Neurofilaments and neurofilament proteins in health and disease. Cold Spring Harb Perspect Biol 9:a018309.

Zai LJ, Yoo S, Wrathall JR (2005) Increased growth factor expression and cell proliferation after contusive spinal cord injury. Brain Res 1052:147-155.

Zanconato F, Cordenonsi M, Piccolo S (2016) YAP/TAZ at the roots of cancer. Cancer Cell 29:783-803.

Zhang HY, Zhang X, Wang ZG, Shi HX, Wu FZ, Lin BB, Xu XL, Wang XJ, Fu XB, Li ZY, Shen CJ, Li XK, Xiao J (2013a) Exogenous basic fibroblast growth factor inhibits ER stress-induced apoptosis and improves recovery from spinal cord injury. CNS Neurosci Ther 19:20-29.

Zhang HY, Wang ZG, Wu FZ, Kong XX, Yang J, Lin BB, Zhu SP, Lin L, Gan CS, Fu XB, Li XK, Xu HZ, Xiao J (2013b) Regulation of autophagy and ubiquitinated protein accumulation by bFGF promotes functional recovery and neural protection in a rat model of spinal cord injury. Mol Neurobiol 48:452-464.

Zhang M, Tao W, Yuan Z, Liu Y (2017) Mst-1 deficiency promotes posttraumatic spinal motor neuron survival via enhancement of autophagy flux. J Neurochem 143:244-256.

Zhang P, Wang T, Zhang D, Zhang Z, Yuan S, Zhang J, Cao J, Li H, Li X, Shen H, Chen G (2019) Exploration of MST1-mediated secondary brain injury induced by intracerebral hemorrhage in rats via hippo signaling pathway. Transl Stroke Res 10:729-743.

Zhang S, Chen Q, Liu Q, Li Y, Sun X, Hong L, Ji S, Liu C, Geng J, Zhang W, Lu Z, Yin ZY, Zeng Y, Lin KH, Wu Q, Li Q, Nakayama K, Nakayama KI, Deng $\mathrm{X}$, Johnson RL, et al. (2017) Hippo signaling suppresses cell ploidy and tumorigenesis through Skp2. Cancer Cell 31:669-684.e7.

Zhou Y, Wang Z, Li J, Li X, Xiao J (2018) Fibroblast growth factors in the management of spinal cord injury. J Cell Mol Med 22:25-37.

Zittermann SI, Issekutz AC (2006) Basic fibroblast growth factor (bFGF, FGF-2) potentiates leukocyte recruitment to inflammation by enhancing endothelial adhesion molecule expression. J Pathol 168:835-846. 